\title{
LAS OBSERVACIONES DE LOS OBISPOS CHILENOS A LOS PROYECTOS DE LIBRO IV, DE DELICTIS ET POENIS, Y LIBRO V, DE IUDICIIS ECCLESIASTICIS, DEL CÓDIGO DE DERECHO CANÓNICO DE 1917
}

\author{
THE CHILEAN BISHOPS' COMMENTARIES TO THE PROJECTS OF \\ BOOK IV, DE DELICTIS ET POENIS, AND BOOK V, DE IUDICIIS \\ ECCLESIASTICIS, FOR THE NEW CANONICAL LAW CODE OF 1917
}

\section{Carlos Salinas ARANEDA ${ }^{1}$}

\begin{abstract}
RESUMEN: La redacción del primer Código de Derecho Canónico que tuvo la Iglesia latina fue ordenada por el papa san Pío X en 1904. La tarea codificadora, empero, no fue obra de un grupo cerrado de expertos, sino que tuvo en cuenta el parecer del episcopado latino, el que fue consultado en dos momentos diferentes; en ambos se pidió la opinión de los obispos chilenos. En este trabajo se estudia, a partir de la documentación guardada en el Archivo Secreto Vaticano, las observaciones de los obispos de la provincia eclesiástica chilena a los proyectos de libros IV, De delictis et poenis, y V, De iudiciis ecclesiasticis, del código canónico que les fueran enviados en 1913 y 1914.
\end{abstract}

Palabras clave: Codificación canónica, Proyectos de Código de Derecho Canónico de 1917, obispos chilenos, animadversiones episcoporum.

ABSTRACT: The first Canonical Law Code drafted by the Latin Catholic Church was mandated by Pope Saint Pious X in 1904. However, the mission was not the work of a close group of experts, but considered in two separate occasions the Latin Episcopate opinions and in both, the Chilean opinions of Chilean bishops. Starting from the documents of the Vatican Secret Archive, this paper studies the observations made by the Chilean catholic bishops to the new Book IV, named De delictis et poenis, and Book V, named De iudiciis ecclesiasticis, for the Canonical Code sent in 1913 and 1914.

Key words: Canonical codification, drafts of Canonical Law Code of 1917, Chilean catholic bishops, animadversiones episcoporum.

\section{LOS PROYECTOS DE CODEX IURIS CANONICI}

La tarea de elaborar un Codex Iuris Canonici que sustituyera al Corpus fue iniciada por el papa san Pío X (1903-1914) a poco de haber iniciado su pontificado en los albores del siglo $\mathrm{XX}^{2}$. Lo hizo mediante el motu proprio Arduum sane munus, de 19 de

\footnotetext{
${ }^{1}$ Licenciado en Ciencias Jurídicas de la Pontificia Universidad Católica de Valparaiso, Licenciado y Doctor en Derecho Universidad Complutense de Madrid, Licenciado en Derecho Canónico Universidad de Salamanca, Doctor en Derecho Canónico Pontificia Universidad Santo Tomas de Aquino, Profesor titular de la Pontificia Universidad Católica de Valparaíso. Correo electrónico: csalinas@ucv.cl

${ }^{2}$ Una síntesis de la historia de la codificación del derecho canónico de 1917 en SALINAS ARANEDA (2008a) con bibliografía.
} 
marzo de $1904^{3}$, mediante el cual creó una comisión pontificia encargada de asumir la codificación del derecho de la Iglesia ${ }^{4}$. La elaboración del código, sin embargo, no fue una tarea de un grupo cerrado de iniciados, sino que, contando con el trabajo de un número importante de expertos bajo la dirección de Pedro Gasparri5 , el mismo motu proprio dispuso la intervención de todo el episcopado latino ${ }^{6}$. De esta manera, una de las principales características del proceso de codificación del derecho canónico de 1917 consistió en la participación del episcopado, promovida por la misma Santa Sede, en la elaboración del Codex. Dicha participación, por cierto, la primera realizada históricamente por la Iglesia al emprender la tarea de elaborar un cuerpo legislativo universal, se articuló en dos grandes momentos: el primero, al inicio de los trabajos de codificación, a través de los Postulata episcoporum; el segundo, en pleno proceso codificador, cuando se estaba llegando a la fase conclusiva del mismo, a través de las Animadversiones episcoporum. De ambos momentos, es el segundo el que ahora me interesa.

Una vez que se recibieron en Roma las respuestas de los obispos a la primera consulta que se les había formulado7 ${ }^{7}$, las que se habían recogido en un libro redactado por el consultor Bernardin Klumper ${ }^{8}$, el proceso de codificación siguió su desarrollo con la preparación de proyectos parciales, los que, una vez terminados, dieron origen a una nueva consulta al episcopado de todo el mundo. Dicha consulta, que se hizo entre los años 1912 y 1914, contó con la oposición de algunos cardenales ${ }^{9}$, pero fue autorizada expresamente por san Pío X y se hizo enviando los distintos proyectos parciales a todos los obispos y prelados de la Iglesia latina que, de acuerdo con los cánones vigentes, hubiesen debido ser convocados a un eventual Concilio Ecuménico, incluidos los vicarios y prefectos apostólicos.

\footnotetext{
${ }^{3}$ Publicado en Acta Sanctae Sedis (1903-1904), vol. 36, pp. 549-551. El motu proprio lleva la fecha 14 de abril de 1904, pero parece que se trata de un error de imprenta, pues en la carta circular Pergratum mibi, fechada el 25 de marzo de 1904, hay una referencia expresa al motu proprio Arduum sane munus. Son de esta opinión, LLOBELL et al. (1999) p. 34 n. 30. Sobre los inicios de la codificación piobenedictina puede verse FANTAPpiè (2002) pp. 16-83. Del mismo autor puede verse su libro más reciente Fantappié (2008) 2 vols., con bibliografía actualizada.

${ }^{4}$ La nómina de sus integrantes en Acta Sanctae Sedis (1903-1904), vol. 36, p. 551.

${ }^{5}$ Antiguo profesor en el Instituto Católico de Paris, entonces arzobispo titular de Cesarea y secretario de la S. Congregación de asuntos eclesiásticos extraordinarios, a quien se le nombró al mismo tiempo presidente de la Comisión de consultores. Posteriormente sería creado cardenal (1907).

${ }^{6}$ En la decisión cuarta el papa manifestaba su deseo de que todo el episcopado, conformándose a las reglas que serían dadas en tiempo oportuno, colaboraran y concurrieran a esta obra tan importante: "IV. Volumus autem universum episcopatum, iuxta normas opportune tradendas, in gravissimum hoc opus conspirare atque concurrere".

7 Para una exposición general de los postulata de los obispos chilenos en respuesta a la primera de las consultas hecha en 1904 puede verse SALINAS (2008b). Para los postulata del obispo de Ancud, Ramón Ángel Jara, véase SAlinaS (2008c). Para los postulata de los obispos chilenos sobre el matrimonio, véase SAlinas (2008d). Para los postulata del obispo de Concepción, Plácido Labarca, véase SALINAS (2008e). Un proyecto parcial de código canónico fue presentado por el obispo Rafael Fernández Concha, cuyo texto y estudio puede verse en SALINAS (2007).

${ }^{8}$ Codex Iuris Canonici (1905).

${ }^{9}$ Entendían que el envío de los ejemplares, la espera de las respuestas de los obispos y el análisis de las mismas retrasarían la promulgación del código.
} 
Por medio de una carta circular firmada por el cardenal Pedro Gasparri, presidente de la comisión codificadora, fechada el 20 de marzo de 1912, se envió a los obispos y a los superiores generales de las órdenes religiosas el proyecto de libro primero, Normae generales, y del libro segundo, De personis, recogidos los dos en un solo volumen ${ }^{10}$. Según las instrucciones que se daban a los obispos en dicha circular, podían proceder al examen de los cánones contenidos en cada uno de los dos proyectos valiéndose de tres expertos en derecho canónico, clérigos regulares o seculares, pero, tanto los obispos como los consultores quedaban obligados al secreto pontificio ${ }^{11}$; las observaciones debían ser enviadas a la Santa Sede no más allá de los seis meses de haber recibido el proyecto. Un año después, el 1 de abril de 1913, se envió el Libro tercero, De rebus ${ }^{12}$, anunciándose el envío del Libro cuarto, De delictis et poenis ${ }^{13}$, y del Libro quinto, De iudicis ecclesiasticis ${ }^{14}$, que les serían transmitidos, respectivamente, el 1 de julio de 1913 y el 15 de noviembre de $1914^{15}$. La numeración de los cánones no era única y continua para todos estos proyectos parciales, sino que se iniciaba en cada uno de los volúmenes. Y todos ellos, con excepción del quinto, llevaban, a pie de página, notas en las que se individualizaban la o las fuentes de donde había sido tomado el respectivo canon; según se indicaba en la portada de cada uno de estos volúmenes, ellas correspondían al cardenal Gasparri. La falta de notas en el último de los libros se decidió para acelerar los trabajos de impresión y distribución y no porque se considerasen poco útiles.

Las respuestas enviadas en esta oportunidad por los obispos, los ordinarios y los superiores religiosos consultados dieron origen a las Animadversiones Episcoporum u observaciones de los obispos a los diversos proyectos parciales de Código de Derecho Canónico elaborados por la comisión de codificación. Las Animadversiones, nada más llegar a Roma, eran clasificadas y ordenadas según la numeración que tenían los cánones respectivos en los proyectos. Algunas de estas observaciones fueron enviadas por los obispos individualmente, otras conjuntamente con los demás obispos de la provincia eclesiástica y su metropolitano. Y como había sucedido con los Postulata, ahora las Animadversiones fueron igualmente impresas en textos que, al igual que había sucedido la primera vez, permanecieron en estricta reserva ${ }^{16}$.

La idea de haber sometido los proyectos a las observaciones del episcopado, al final, se reveló feliz y fecunda. De hecho las diferencias entre los proyectos y el texto finalmente publicado no son de mera forma, sino que son más importantes y profun-

\footnotetext{
10 Schema (1912). El libro I lo componían 79 cánones y el libro II, 567 cánones.

11 Según el propio cardenal Gasparri, el secreto pontificio fue rigurosamente guardado, a pesar de que eran cerca de cinco mil las personas consultadas. GASPARRI (1937) p. 8.

12 Schema (1913a) contenía 831 cánones.

13 Schema (1913b) contenía 227 cánones.

14 Schema (1914) contenía 773 cánones.

15 El texto de la misma en LlObell et al. (1999) pp. 841-842.

16 Riassunto delle osservazioni dei Vescovi e Superiori Regolari al Lib. I e II del Codice, en el que, en un centenar de páginas, se hace una síntesis de las mismas; Observationes Epicoporum et Superiorum Regularium in Lib. I et II Codicis, más breve en que se recogen las observaciones llegadas con retraso a Roma. Ambos textos impresos se encuentran en la biblioteca de la Pontificia Universidad Gregoriana de Roma. Ibíd., p. 85.
} 
das ${ }^{17}$. Las observaciones de los obispos, una vez llegadas a Roma, eran revisadas por el cardenal Gasparri, quien con una raya hecha con un lapicero sobre el texto de la observación, marcaba aquellas que eran tomadas en cuenta de cara a la revisión de los proyectos $^{18}$.

De los proyectos de los cinco libros en que estaba concebido el código que se elaboraba, me interesan de momento los dos últimos, el proyecto del libro IV, referido a los delitos y las penas, y el proyecto de libro $\mathrm{V}$, relacionado a los juicios eclesiásticos ${ }^{19}$.

\section{LOS OBISPOS CHILENOS CONSULTADOS}

Los primeros proyectos parciales, referidos a los libros I y II, fueron enviados a todos los obispos y prelados de la Iglesia latina que, de acuerdo con los cánones vigentes, hubiesen debido ser convocados a un eventual Concilio Ecuménico, incluidos los vicarios y prefectos apostólicos. Los proyectos de libro IV y V, en cambio, solo fueron enviados a los arzobispos y sus sufragáneos. En los años 1913 y 1914, años en que se enviaron ambos proyectos, era arzobispo de Santiago, Juan Ignacio González Eyzaguirre ${ }^{20}$; obispo de La Serena, Ramón Ángel Jara Ruz ${ }^{21}$; obispo de Concepción, Luis Enrique Izquierdo Vargas ${ }^{22}$ y Obispo de Ancud, fray Pedro Armengol Valenzuela Poblete, O. de M. ${ }^{23}$. A ellos correspondió conocer dichos proyectos y formular las observaciones que su lectura les sugiriere.

17 Un primer análisis en lo que se refiere al derecho matrimonial en VeTULANI (1942), col. 930-933, donde se identifica una larga y significativa lista de cánones agregados al proyecto de 1912, además de otros que fueron suprimidos.

${ }^{18}$ De esta manera, la lectura actual de estos informes permite advertir que algunas de las observaciones planteadas aparecen con una raya, normalmente serpenteante, sobre el texto y otras sin raya alguna. La raya está hecha con tinta y no dificulta la lectura de las observaciones. FALCHI (2006) p. 335-336.

19 Sobre las observaciones de los obispos chilenos a los libros I y II, véase SALINAS (2009). Sobre el proyecto de libro III, referido a las cosas, no he encontrado observación alguna de los obispos chilenos.

${ }^{20}$ Nacido el 12 de julio de 1844, san Pío X lo había elegido obispo titular de Flaviades el 18 de abril de 1907; fue promovido al arzobispado de Santiago por el mismo san Pío X el 8 de agosto de 1908, sucediendo a Mariano Casanova que había fallecido el 16 de mayo de ese mismo año; falleció en Santiago el 9 de junio de 1918. Para las diligencias relativas a su preconización como arzobispo de Santiago, véase Retamal (2005) pp. 1122-1126. GONZÁLEZ (2003), pp. 57-347. OVIEDO (1996) pp. 131-132; DUCASSE (2008) p. 169.

${ }^{21}$ Nacido el 2 de agosto de 1852, León XIII lo había elegido obispo de Ancud el 2 de mayo de 1898. San Pío X lo trasladó a La Serena el 31 de agosto de 1909, sucediendo a Florencio Fontecilla Sánchez, fallecido el 1 de marzo de 1909. Falleció en La Serena el 9 de marzo de 1917. Acerca de su traslado al obispado de La Serena, véase la carta que le dirige san Pío X, en Boletín Eclesiástico del Arzobispado de Santiago (19081910), vol. 17, pp. 671-672, ahora en ReTAMAL (2005) pp. 1158-1159; OvIEDO (1996), pp. 145-147; DUCASSE (2008), pp. 185-186.

22 Nacido el 21 de enero de 1861, san Pío X lo eligió obispo de Concepción el 26 de enero de 1906, sucediendo a Plácido Labarca, fallecido el 9 de octubre de 1905. Falleció el 7 de agosto de 1917. Oviedo (1996), pp. 143-144; DUCASSE (2008), p. 183.

${ }^{23}$ Nacido el 5 de julio de 1853, san Pío X lo eligió obispo de San Carlos de Ancud, el 30 de junio de 1910, sucediendo a Ramón Ángel Jara Ruz, trasladado al obispado de La Serena. En 1880 había sido elegido maestro general de la Orden de la Merced, la que gobernó hasta que fue elegido obispo de Ancud. El 9 de enero de 1904 el mismo papa lo había nombrado consultor para participar en la redacción del código canónico que se había empezado a preparar. Renunció al obispado de Ancud en 1916. Oviedo (1996), pp. 234-235; DUCASSE (2008), pp. 290-291. 
De los obispos que participaron en el informe de cada uno de estos dos libros, dos de ellos habían participado en el proceso de codificación desde los inicios del mismo en 1904: el obispo de Ancud, fray Pedro Armengol Valenzuela, quien había sido incluido en la primera lista de consultores elaborada en dicho año al inicio mismo de la codificación canónica ${ }^{24}$, mientras se desempeñaba en Roma como maestro general de la Orden de la Merced; y el obispo de La Serena, Ramón Ángel Jara, quien había participado en 1904 en el primer informe enviado a Roma, cuando entonces era obispo de Ancud, no solo uniéndose al informe enviado por el arzobispo Mariano Casanova, sino agregando propuestas propias ${ }^{25}$. Los otros dos prelados, el arzobispo de Santiago, Juan Ignacio González Eyzaguirre, y el obispo de Concepción, Luis Enrique Izquierdo Vargas, se enfrentaron por primera vez al proceso codificador cuando, en 1912, fueron enviados en un solo volumen los proyectos de los libros I y II del Código Canónico ${ }^{26}$.

Sabemos que según las instrucciones que se dieron a los obispos en la circular con que se envió el proyecto de ambos libros, podían proceder al examen de los cánones contenidos en cada uno de ellos valiéndose de algunos expertos en derecho canónico, clérigos regulares o seculares, pero tanto los obispos como los consultores quedaban obligados al secreto pontificio ${ }^{27}$. No hay antecedentes sobre quiénes pudieron haber asesorado a los obispos chilenos al momento de emitir sus informes sobre los libros IV y $\mathrm{V}$, a diferencia de lo que sucedió cuando se envió a Roma el informe de los libros I y II, oportunidad en la que les colaboró el presbítero Carlos Silva Cotapos ${ }^{28}$, a la sazón secretario de cámara del arzobispo de Santiago, quien le había encargado "estudiar el proyecto de Código Canónico" y que en la asamblea trienal de los obispos de la provincia eclesiástica chilena, celebrada en septiembre de 1912, propuso, en la sesión del 5 de septiembre de 1912, cinco indicaciones, tres de las cuales se incorporaron al informe final ${ }^{29}$. Es posible, en todo caso, que haya conocido, al menos informalmente, los proyectos de libros IV y V, pues se desempeñó hasta 1914 como secretario del arzobispo y entre 1915 y 1918 fue provisor del arzobispado. Pero no hay constancia de su participación formal en los informes enviados a Roma.

\footnotetext{
${ }^{24}$ La nómina de los mismos, entre quienes se menciona a fray Pedro Armengol Valenzuela, fue comunicada por el Secretario de Estado, Rafael Merry del Val, a los obispos del mundo, por carta circular Pergratum mibi, de 25 de marzo de 1904. Su texto en Actae Sanctae Sedis (1903-1904), vol. 36, pp. 603-604.

${ }^{25}$ SALINAS (2008c) pp. 161-189.

26 SALINAS (2009).

27 En la carta con la que envió el proyecto de libro V, De iudiciis ecclesiasticus, se permitía que los prelados examinaran el proyecto con uno o dos varones peritos en derecho canónico, del clero secular o religioso. El texto de la carta en LLOBELL et al. (1999) pp. 841-842.

${ }^{28}$ Nacido el 10 de mayo de 1868, fue ordenado sacerdote el 21 de septiembre de 1891, un año después de haber obtenido su título de abogado en la Universidad de Chile. Era secretario desde 1902 y lo fue hasta 1914. Al año siguiente fue provisor y vicario general hasta 1918, el año en que entró en vigencia el nuevo código. Desde 1907 era canónigo de la catedral de Santiago. Benedicto XV lo eligió obispo de La Serena el 20 de febrero de 1918. Posteriormente fue el primer obispo de Talca desde 1926 a 1939. Falleció en 1941. OVIEDO (1996) pp. 215-216; DUCASSE (2008), pp. 268-269.

${ }^{29} \mathrm{El}$ acta de la asamblea trienal en lo que se refiere a los proyectos de libros I y II del Código de Derecho Canónico, en ARChivo (s.d.) pp. 37-43, publicado en Retamal (2005) pp. 1264-1266.
} 


\section{OBSERVACIONES AL PROYECTO DE LIBRO IV, DE DELICTIS ET POENIS}

El proyecto de libro IV, referido a los delitos y las penas ${ }^{30}$, fue enviado el 1 de julio de 1913, pero no hay constancia de la fecha de su arribo a Chile. Constaba de 227 cánones distribuidos en tres partes referidas, respectivamente, a los delitos (Pars prima, De delictis) $)^{31}$, a las penas (Pars secunda, De poenis) $)^{32}$ y a los delitos singulares y sus penas (Pars tertia, De singulis delictis eorumque poenis) ${ }^{33}$.

La respuesta de los obispos chilenos fue el 12 de marzo de 1914. Se hizo mediante una carta escrita en un folio por el anverso, en máquina de escribir, firmada solo por el arzobispo de Santiago, en la que se incluían tan solo dos propuestas de modificación, ambas meramente formales. En la misma carta se hacía presente que "los ilustrísimos obispos sufragáneos opinaron que nada debia corregirse".

\section{REFORMULAR EL CANON RELATIVO A LOS EFECTOS DEL ENTREDICHO EN TERRITORIO CON ÚNICA O VARIAS IGLESIAS}

La observación era al canon 76 del proyecto de libro $\mathrm{IV}^{34}$, canon que regulaba los efectos del entredicho territorial cuando en el lugar había solo una iglesia ( $\$ 1$ ) o había otras iglesias $(\$ 2)$ o el entredicho era para una capilla o un altar $(\$ 3)$ y la administración de sacramentos y la celebración de otros oficios divinos en dichos lugares $(\$ 4)^{35}$. Entendía

\footnotetext{
30 Véase antes nota 12.

31 Constaba de tres títulos: Tit. I: De natura delicti eiusque divisione (can. 1-4). Tit. II: De imputabilitate delicti, de causis illam aggravantibus, vel minuentibus et de iuridicis delicti effectibus (can. 5-17). Tit. III: De conato delicti (can. 18-19).

32 Constaba de dos secciones y siete títulos: Sectio I: De poenis in genere. Tit. I: De coactiva Ecclesiae potestate, de poenarum notione, speciebus, interpretatione atque applicatione (can. 20-26). Tit. II: De superiore potestatem coactivam habente (can. 27-31). Tit. III: Se subiecto coactivae potestati obnoxio (can. 32-41). Tit. IV: De poenarum remissione (can. 42-46). Sectio II: De poenis in specie. Tit. V: De censuris. Caput I: De censuris in genere (can. 47-59). Caput II: De censuris in specie (can. 60-61). Art. I: De excommunicatione (can. 62-72). Art. II: De interdicto (can. 73-89). Tit. VI: De poenis vindicativis (can. 90-94). Caput I: De poenis vindicativis communibus (can. 95-109). Tit. VII: De remediis poenalibus et poenitentiis. Caput I: De remediis peonalibus (can. 110-113). Caput II: De poenitentiis (can. 114-115).

33 Constaba de nueve títulos: Tit. I: De delictis contra fidem (can. 116-121). Tit. II: De delictis contra religionem (can. 122-131). Tit. III: De delictis contra auctoritates, personas, res ecclesiasticas (can. 132-153). Tit. IV: De delictis contra vitam, libertatem, proprietatem, bonam famam ac bonos mores (can. 154-165). Tit. V: De crimine falsi (can. 166-170). Tit. VI: De delictis in ministratione vel susceptione ordinum aliorumque sacramentorum (can. 171-182). Tit. VII: De delictis contra obligationes proprias status clericalis vel religiosi (can. 183-200). Tit. VIII: De delictis in collatione, susceptione, et dimissione dignitatum, officiorum et beneficiorum ecclesiasticorum (can. 201-214). Tit. IX: De abusu potestatis vel officii ecclesiastici (can. 215227).

${ }^{34}$ Proyecto de libro IV: De delictis et poenis. Pars secunda: De poenis. Sectio II: De poenis in specie. Tit. V: De censuris. Caput II: De censuris in specie. Art. II: De interdicto.

35 Proyecto de libro IV, canon 76: "\$ 1 . Si in territorio unica sit ecclesia et haec interdicatur, valet pro ea praescriptum can. 75. $\$ 2$. Si aliae quoque sint ecclesiae: $1^{\circ}$ Interdicta ecclesia quae nec capitularis sit nec paroecialis, nullum divinum officium vel sacrum ritum inibi celebrari licet; $2^{\circ}$ Interdicta ecclesia capitulari, at non interdicto Capitulo, in ea permittuntur tantum celebratio Misae conventualis et recitatio horarum canonicarum in choro; $3^{\circ}$ Ordinarius autem, si id necessarium vel opportunum pro infirmis prudenter iudicaverit,
} 
el arzobispo ${ }^{36}$ que el canon no estaba rectamente ordenado, porque no se veía una relación suficiente entre las leyes contenidas en los parágrafos 3 y 4, por una parte, y las de los parágrafos 1 y 2, por otra. Según él, la norma del parágrafo 3 quizá podía constituirse en un canon separado; y el parágrafo 4 había que suprimirlo porque establecía lo mismo que el canon $75 \$ 2^{37}$.

El entredicho era una especie de censura, esto es, según Donoso ${ }^{38}$, "una pena eclesiástica medicinal, por la cual se priva al hombre bautizado, delincuente y contumaz, de la participación de algunos de los bienes espirituales de que tienen derecho a participar todos los fieles". Podía ser considerado también como pena vindicativa, en cuyo caso el entredicho

permitiere potest ut in memoratis ecclesiis interdictis asservetur Sanctissimum Sacramentum et Missa ad renovandas sacras species celebretur; $4^{\circ}$ Interdicta ecclesia paroeciali, permittuntur, tantum, nisi interdicto decretum aliquid excipiat, asservatio Sanctissimi Sacramenti pro viatico ministrando, Missae ad renovandas sacras species celebratio, administratio sacramenti baptismatis, poenitentiae, extremae unctionis, benedictio aquae baptismalis et, si ecclesia fuerit cathedralis, etiam sacrorum oleorum, adsistentia matrimonii et mortuorum exequiae sine solemnitatibus, praedicatio verbo Dei. $\$ 3$. Interdicta capella seu altari alicuius ecclesiae, nullum sacrum officium sea sacer ritus ibidem celebretur. $\$ 4$. In sacramentorum administratione aliorumve divinorum officiorum celebratione servetur praescriptum can. $75 \$ 2 "=" \$ 1$. Si en un territorio hubiera una sola iglesia y esta está en entredicho, vale a favor de ella lo prescrito en el canon 75 . $\$ 2$. Si algunas también son iglesias: $1^{\circ}$ En una iglesia en entredicho que no sea ni capitular ni parroquial, no está permitido que se celebre allí ningún oficio divino o rito sagrado; $2^{\circ}$ Estando en entredicho una iglesia capitular, pero no estando en entredicho el Capítulo, es permitido en ella solo la celebración de la Misa conventual y la recitación de la horas canónicas en el coro; $3^{\circ}$ Sin embargo, el Ordinario, si prudentemente lo juzga necesario o conveniente en favor de los enfermos, puede permitir que en las iglesias famosas en entredicho se guarde el Santísimo Sacramento y se celebre la Misa para que las especies sagradas sean renovadas; $4^{\circ}$ Estando en entredicho una iglesia parroquial, se permiten, solamente, a menos que el decreto de entredicho estipule alguna cosa, la custodia del Santísimo Sacramento para la administración del viático, la celebración de la Misa para la renovación de las especies sagradas, la administración del sacramento del bautismo, de la penitencia, de la extremaunción, la bendición del agua bautismal y, si la iglesia fuera catedral, también la bendición de los óleos sagrados, la asistencia a los matrimonios y las exequias mortuorias sin solemnidades, y la predicación de la palabra de Dios. $\$ 3$. En una capilla en entredicho o en un altar de alguna iglesia, no se puede celebrar allí ningún oficio sagrado o rito sagrado. $\$ 4$. En la administración de los sacramentos o en la celebración de algunos oficios divinos estése a lo prescrito en el can. $75 \$ 2$ ".

${ }^{36}$ Animadersiones 1: "Canon 76 non videtur recte digestus quum leges $\mathbb{S} 3$ et $\mathbb{S} 4$ et leges $\mathbb{S} 1$ et 2 non satis arcto nexu teneantur. Lex enim $\mathbb{S} 3$ forte canonem separatum constituere poterit; et $\mathbb{S} 4$ delendum erit quia idem statuit quod canon 75 \& 2".

37 Proyecto de libro IV, canon 75: "\$1. Interdicto territorio, ibidem permittuntur tantum, nisi interdicto decretum aliquid excipiat, Missarum celebratio, administratio sacramento baptismatis, confirmationis in periculo mortis, Eucharistiae, poenitentiae, extremae unctionis, assistentia matrimoniis ac mortuorum exequias sine tamen solemnitatibus, benedictio aquae baptismalis et sacrorum oleorum, recitatio horarum canonicarum in choro, praedicatio verbi Dei. $\$ 2$. In administratione sacramentorum et celebratione divinorum officiorum de quibus in $\mathbb{S} 1$, vetatur sonitus campanarum, organorum, aliorumve instrumentorum musicalium, cantus et pompa in sacra supellectile" $=" \$ 1$. En un territorio en entredicho, solo se permiten allí, a no ser que el decreto de entredicho establezca otra cosa, la celebración de las Misas, la administración de los sacramentos del bautismo, de la confirmación en peligro de muerte, de la Eucaristía, de la penitencia, de la extremaunción, la asistencia de matrimonios y la exequias mortuorias sin ceremonias solemnes, la bendición del agua bautismal y de los óleos sagrados, la recitación de las horas canónicas en el coro, la predicación de la palabra de Dios. $\$ 2$. En la administración de los sacramentos y la celebración de los oficios divinos de que se trata en el $₫ 1$, está vedado el sonido de las campanas, de los órganos y de cualquiera otros instrumentos musicales, el canto y la pompa en el sagrado ajuar".

${ }^{38}$ DONOSO (1849) p. 423. 
era "la exclusión de ciertos bienes a que tiene derecho cada uno de los fieles, infligida a alguno por razón de delito" 39 . En uno y otro caso el entredicho privaba de los mismos bienes: la celebración y asistencia a los oficios divinos, la recepción de los sacramentos, la sepultura eclesiástica. Se diferenciaban en que el entredicho como censura tenía por objeto primario "quebrantar la contumacia del delincuente" en tanto que el penal se decretaba independientemente de su contumacia; consecuencia de ello era que el entredicho censura no se limitaba a tiempo determinado y se quitaba por absolución, en tanto que el entredicho pena se decretaba por tiempo determinado y cesaba por lapso de tiempo determinado.

El entredicho podía ser local, personal o mixto. El local, que es el que me interesa, afectaba a un lugar determinado, prohibiendo que en él se ejerciesen "las funciones sagradas vedadas en tiempo de entredicho", pero no ligaba a las personas que existían fuera del lugar respectivo. Cualquiera que fuese la modalidad del entredicho, los efectos del mismo eran tres: la privación de algunos sacramentos, la privación de los oficios divinos, y la privación de sepultura eclesiástica. Sin embargo, en relación con la privación de los sacramentos, que es una de las materias reguladas por el canon 76 del proyecto de libro IV observada por el arzobispo de Santiago, podía administrarse el bautismo a los párvulos y a los adultos; lo mismo la confirmación, por lo que podía consagrarse el crisma el jueves santo con la solemnidad acostumbrada, pero no podía administrarse la confirmación a las personas especialmente entredichas ni a los que habían motivado un entredicho general. El sacramento de la penitencia podía administrarse no solo a los moribundos, sino también a los sanos, con excepción de que estos hubiesen motivado el entredicho y no hubiesen satisfecho aún ni dado suficiente caución de satisfacción. La Eucaristía solo se permitía administrarla a los enfermos por modo de viático. No podía conferirse la ordenación sacerdotal a personas entredichas ni ordenar en lugares entredichos. Y respecto del matrimonio, este podía celebrarse pero sin la bendición solemne ${ }^{40}$.

El segundo efecto del entredicho, al que también se refería el canon observado por el arzobispo de Santiago, era la privación de los oficios divinos, quedando comprendidos en este concepto la celebración de la Misa, la recitación solemne del oficio público y toda acción ordenada al culto divino, ejercida en nombre de la Iglesia por sus ministros, pero no la predicación dirigida a la corrección e instrucción del pueblo; tampoco quedaban excluidos los ejercicios privados de piedad o devoción ni la recitación privada de las horas canónicas ${ }^{41}$.

La anterior era la disciplina que los cánones 75 y 76 del proyecto de libro IV trataban de regular. Ambos cánones fueron reelaborados en el texto del código finalmente aprobado, en el que fueron los cánones $2271^{42}$ y $2272^{43}$ los que regularon esta

\footnotetext{
39 DONOSO (1849) p. 423.

40 Donoso (1849) p. 425.

41 Donoso (1849) p. 425.

42 CIC 1917, canon 2271: "Si el entredicho es local general y en el decreto del mismo no se dice expresamente lo contrario: $1^{\circ}$ Pueden los clérigos, siempre que ellos no estén personalmente entredichos, celebrar privadamente todos los oficios divinos y ritos sagrados en cualquier iglesia u oratorio, a puerta cerrada, en voz baja y sin tocar las campanas; $2^{\circ}$ En la iglesia catedral y en las parroquiales o en la iglesia que es unica en la localidad, y solo en estas, se permite: la celebración de una Misa; el tener reservado el santísimo Sacramento; la administración del
} 
materia. La petición episcopal de que el parágrafo 3 del canon 76, referido al entredicho de una capilla o altar, se transformara en un canon independiente, no fue acogida, pues dicha norma, si bien cambió de ubicación, pasó a ser el parágrafo 1 del canon 2272 . Y en cuanto a la supresión pedida del parágrafo 4 del canon 76 que, en materia de administración de sacramentos se remitía al canon $75 \$ 2$, la remisión quedó incluida en el mismo canon 2272, al referirse al entredicho de una iglesia parroquial.

La reforma que presentan estos dos cánones en el texto final del Codex respecto del proyecto es mayor que la sugerencia formal hecha por el arzobispo chileno, por lo que es posible que, junto a sus observaciones, haya habido otras de otros episcopados que, en su conjunto, hicieran conveniente una nueva formulación de los mismos. Con todo, en el informe original, la primera de las dos observaciones del arzobispo no aparece tarjada, lo que significa que no se consideró lo suficientemente interesante como para haberla tomado en cuenta.

\section{RECTIFICAR LA REMISIÓN HECHA AL CANON QUE REGULA LA ABSOLUCIÓN DE CENSURAS OCULTAS}

La segunda observación del arzobispo de Santiago al proyecto de libro IV fue al canon 94 parágrafo $2^{44}$, que se refería a la dispensa de las censuras latae sententiae dada por el confesor en los casos ocultos ${ }^{45}$, parágrafo en que se hacía una remisión al canon

bautismo, de la Eucaristía y de la penitencia; la asistencia a los matrimonios, pero no la bendición nupcial; las exequias mortuorias, pero sin solemnidad alguna; la bendición del agua bautismal y de los santos óleos y la predicación de la palabra divina. Se prohibe, sin embargo, en estas funciones sagradas el canto y la pompa en los objetos del culto, y el toque de campanas, órgano u otros instrumentos músicos; pero el santo Viático debe llevarse privadamente a los enfermos.

43 CIC 1917, canon 2272: "\$ 1. Tratándose de entredicho local particular, si están en entredicho un altar o una capilla de alguna iglesia, no puede celebrarse en ellos ningún oficio o rito sagrado. $\$ 2$. Si está en entredicho el cementerio, pueden ser sepultados en él los cadáveres de los fieles, pero sin ningún rito eclesiástico. $\$ 3$. Si el entredicho se ha lanzado contra una iglesia determinada o un oratorio: $1^{\circ}$ Si la iglesia es capitular y no está el Cabildo en entredicho, es de aplicación lo que se prescribe en el canon 2271, número $1^{\circ}$, a no ser que el decreto de entredicho disponga que se celebre la Misa conventual y se reciten las horas canónicas en otra iglesia $u$ oratorio. $2^{\circ}$ Si la iglesia es parroquial, debe observarse lo que se dispone en el expresado canon 2272, numero $2^{\circ}$, a no ser que el decreto de entredicho designe otra iglesia en sustitución de aquella para mientras dure el entredicho.

${ }^{4}$ Proyecto de libro IV: De delictis et poenis; Pars secunda: De poenis; Sectio II: De poenis in specie; Tit. VI: De poenis vindicativis.

45 Proyecto de libro IV, canon 94: "\$1. In casibus occultis et urgentioribus, si revera ex observantia poenae vindicativae latae sententiae, reus seipsum proderet cum infamia et scandalo, quilibet confessarius potest in foro sacramentali obligationem servandae peonae suspendere non ultra mensem, iniuncto onere interim recurrendi saltem per epistolam sive per se sive per confessarium ad superiores facultate praeditum et standi eius mandatos. $\$ 2$. Et si in aliquo casu extraordinario hic recursus sit impossibilis, tunc ipsemet confessarius potest dispensationem concedere ad normam can. $59 \mathbb{S}$ " $" \$ 1$. En los casos ocultos y más urgentes, si realmente por observar la pena vindicativa latae sententiae debería el reo delatarse a sí mismo con infamia suya y con escándalo, puede cualquier confesor suspender en el fuero sacramental la obligación de observarla por no más de un mes, imponiéndole la carga de recurrir al menos por carta, por sí mismo o por un confesor, al superior que goce de facultades y la de atenerse a sus mandatos. $\$ 2$. Y si en algún caso extraordinario es imposible este recurso, puede entonces el confesor mismo conceder la dispensa a tenor del canon $59 \$ 2 ”$. 
59 parágrafo 2 del mismo proyecto ${ }^{46}$. Según el arzobispo ${ }^{47}$, en el canon $94 \$ 2$, la cita al canon $59 \$ 2$ debía ser corregida y hacerse al canon $59 \$ 3$. La observación era meramente formal, pero exacta.

El canon 94 del proyecto se transformó en el canon 2290 del Codex, con escasas modificaciones, y en el parágrafo 2 del mismo, la referencia se hizo al parágrafo 3 del canon 2254, canon este que repetía, con variantes escasas, el canon 59 del proyecto. Es decir, la sugerencia episcopal fue atendida y, en la edición final del código, se tuvo cuidado de hacer la remisión exacta. De hecho, en el texto original de la carta enviada por el arzobispo de Santiago, esta segunda observación aparece tarjada, lo que significa, precisamente, que la observación fue recogida por los codificadores.

\section{OBSERVACIONES AL PROYECTO DE LIBRO V, DE IUDICIIS ECCLESIASTICUS}

El proyecto de libro V, referido a los juicios eclesiásticos ${ }^{48}$, fue enviado el 15 de noviembre de $1914^{49}$. Constaba de 773 cánones, distribuidos en cuatro partes referidas, cada una de ellas, a los juicios eclesiásticos en general $^{50}$, a lo que hay que observar en

\footnotetext{
46 Proyecto de libro IV, canon 59: "\$ 1 . In casibus urgentioribus, si nempe censurae latae sententiae exterius servari nequeant sine periculo gravis scandali vel infamiae, aut si durum sit poenitenti in statu gravis peccati permanere per tempus necessarium ut superior habens facultatem provideat, tunc quilibet confessarius in foro sacramentali ab eisdem, utcumque reservatis, absolvere potest, iniuncto onere recurrendi, sub poena reincidentiae, intra mensem saltem per epistolam sive per se sive per confessarium ad superiores praeditum facultate et standi eius mandatis. $\$ 2$. Hic recursos fieri nequit ad confessarium habentem facultates pro foro sacramentali tantum; sed nil impedit quominus poenitens, etiam post obtentam, ut supra, absolutionem, facto quoque recurso ad superiores, alium adeat confessarium facultate praeditum ab eoque, repetita confessione saltem delicti cum censura, consequatur absolutionem. $\$ 3$. Quod si in casu aliquo extraordinario hic recursus sit moraliter impossibilis, tunc ipsemet confessarius potest absolutionem concedere sine onere de quo supra, iniunctis tamen de iure iniungendis, et imposita congrua poenitentia et satisfactione pro censura ita ut poenitens, nisi intra congruum tempos a confessario praefiniendum poenitentiam egerit ac satisfactionem dederit, reincidat in censuram" $=" \$ 1$. En los casos más urgentes, esto es, cuando las censuras latae sententiae no pueden observarse exteriormente sin peligro de escándalo grave o de infamia, o si le es duro al penitente permanecer en pecado mortal durante el tiempo necesario para que el superior competente provea, entonces cualquier confesor puede en el fuero sacramental absolver de dichas censuras, de cualquier manera que estén reservadas, imponiendo bajo pena de reincidencia la obligación de recurrir en el plazo de un mes, al menos por carta o por él o por el confesor, al superior que goce de las facultades al efecto y la obligación también de atenerse a sus mandatos. $\$ 2$. Este recurso se hace inválidamente al confesor que solo tiene facultades en el fuero sacramental; pero no hay inconveniente alguno en que el penitente, aun en el caso de haber recibido la absolución en la forma expuesta y de haber recurrido ya al superior, acuda a otro confesor que tenga facultades y, repitiendo la confesión por lo menos del delito castigado con censura, obtenga de él la absolución. $\$ 3$. Y si en algún caso extraordinario es moralmente imposible este recurso, puede el mismo confesor darle la absolución sin imponerle la obligación de recurrir, pero mandándole aquello que en derecho deba mandarse e imponiéndole congrua penitencia y satisfacción por la censura, de tal forma que el penitente incurra de nuevo en ella si dentro de un plazo prudencial, que habrá de fijarle el confesor, no hace penitencia y da satisfacción”.

47 Animadversiones II: “In canone $94 \$ 2$ citatio can. 59 \$ 2 ita corrigenda: can. 59 \$3".

48 Véase antes nota 13.

${ }^{49}$ El texto de la carta en Llobell et al. (1999) pp. 841-842.

${ }^{50}$ Liber Quintus; De iudiciis ecclesiasticis (can. 1-10). Pars prima: De Iudiciis Ecclesiasticis in genere; Sectio I: De Tribunalium ecclesiasticorum ordinatione. Titulus I: De foro competente (can. 11-17). Caput I: De
} 
algunos juicios eclesiásticos ${ }^{51}$, a los procesos administrativos ${ }^{52}$ y a los procesos acerca de la dimisión de religiosos ${ }^{53}$.

competentiae titulis (can. 18-37). Titulus II: De tribunali ordinario primae instantiae. Caput I: De Iudice (can. 38-45). Caput II: De Auditoribus et Relatoribus (can. 46-50). Caput III: De Promotore iustitiae ac vinculi Defensore (can. 51-56). Caput IV: De Notariis et Cancellariis (can. 57-63). Caput V: De Cursoribus et Apparitoribus (can. 64-66). Titulus III: De tribunali ordinario secundae instantiae (can. 67-68). Titulus IV: De Apostolicae Sedis tribunalibus (can. 69). Caput I: De Sacra Romana Rota (can. 70-75). Caput II. De Signatura Apostolica (can. 76-78). Titulus V: De iudice et tribunali delegato (can. 79-80). Titulus VI: De constitutione, iuramento et officio iudicum et tribunales adiutorum (can. 81-90). Titulus VII: De disciplina in tribunalibus servando. Caput I: De loco et tempore iudicci (can. 91-94). Caput II: De personis in iudicio admittendis et de modo confectionis et conservationis actorum (can. 95-101). Sectio II: De processu judiciario generatim. Titulus I: De partibus in causa. Caput I: De actore et reo convento (can. 102-111). Caput II: De procuratoribus ad lites et advocatis (can. 112-124). Titulus II: De actionibus et exceptionibus (can. 125-126). Caput I: De actione adipiscendae possessionis (can. 127-128). Caput II: De actionibus retinendae possessionis (can. 129-132). Caput III: De actionibus recuperandae possessionis seu de spolio (can. 133-135). Caput IV: De sequestratione et inhibitione exercitii iuris (can. 136-140). Caput V: De actionibus ex novi operas nunciatione et damno infecto (can. 141-143). Caput VI: De actionibus ob nullitatem actorum (can. 144-148). Caput VII: De actionibus rescissoriis (can. 149-153). Caput VIII: De actionibus reconventionalibus (can. 154-156). Caput IX: De cumulo actionum (can. 157-160). Caput X: De extintione actionum (can. 161166). Caput XI: De interruptione et peremptione instantiarum (can. 167-173). Caput XII: De renunciatione instantiae vel actibus processus (can. 174-176). Titulus III: De causae introductione (can. 177-182). Titulus IV: De citatione et intimatione actorum iudicialium. Caput I: De citatione, eiusque effectibus (can. 183-190). Caput II: De modo intimandi citations aliaque acta iudicialia (can. 191-200). Titulus V: De dilationum terminis et fatalibus (can. 201-203). Titulus VI: De ordine cognitionum (can. 204-212). Titulus VII: De litis contestatione (can. 213-218). Titulus VIII: De probationibus generatim (can. 219-225). Titulus IX: De confessione, examine et iuramento partium (can. 226-243). Titulus X: De testibus et attestationibus (can. 244). Caput I: Qui testes esse possunt (can. 245-248). Caput II: A quibus, quomodo, et quot testes induci et qui exclude possint (can. 249-254). Caput III: De citatione testium (can. 255-258). Caput IV: De iureiurando testium (can. 259-265). Caput V: De loco et modo examinis (can. 266-277). Caput VI: Quae testes reticere et quae secreta servari possint vel debeant (can. 278-280). Caput VII: De testimoniarum evulgatione deque reprobatione testium tum quod dicta attinet tum quod examen (can. 281-285). Caput VIII: De indemnitate testium (can. 286-288). Caput IX: De testimoniorum fide (can. 289-292). Titulus IX [sic = XI]: De peritis (can. 293-308). Titulus XII: De accessu et recognitione iudiciali (can. 309-316). Titulus XIII: De probatione per instrumenta. Caput I: De natura et fide instrumentorum (can. 317-327). Caput II: De productione documentorum et actione ad exhibendum (can. 328-335). Titulus XIV: De praesumptionibus (can. 336-339). Titulus XV: De causis incidentibus in genere (can. 340-346). Titulus XVI: De quibusdam specialibus causis incidentibus. Caput I: De contumacia (can. 347-357). Caput II: De interventu tertii in causa (can. 358359). Caput II: De attentatis lite pendente (can. 360-364). Titulus XVII: De processus publicatione, de conclusione in causa et de causae discussione (can. 365-377). Titulus XVIII: De sententia (can. 378-389). Titulus XIX: De querela nullitatis adversus sententiam (can. 390-392). Titulus XX: De apellatione (can. $393-$ 412). Titulus XXI: De oppositione tertii (can. 413-416). Titulus XXII: De re iudicata (can. 417-421). Titulus XXIII: De expensas iudicialibus et gratuito patrocinio. Caput I: De expensas iudicialibus (can. 422427). Caput II: De gratuito patrocinio, aut expensarum iudicialium reductione (can. 428-432). Titulus XXIV: De executione sententiae (can. 433-439).

51 Proyecto de libro V. Pars altera: De iis quae in nonnullis iudiciis ecclesiasticis servanda sunt. Sectio I: De iudicio criminali (can. 440-441). Titulus I: De ordinario criminali processu. Caput I: De accusatoria actione, denuntiatione et querela damni (can. 442-450). Caput II: De inquisitione (can. 451-459). Caput III: De correctione delinquentis (can. 460-468). Caput IV: De instructione processus criminales et de rei constitutione (can. 469-476). Titulus II: De processu criminali ex notorio (can. 477-480). Sectio II: De causis matrimonialibus et contra sacram ordinationem. Titulus I: De causis matrimonialibus. Caput I: De foro competente (can. 481-486). Caput II: De tribunali constituendo (can. 487-490). Caput III: De iure accusandi matrimonium et postulando dispensationem super rato (can. 491-494). Caput IV: De probationibus (can. 495-498). Caput V: De inspectione corporali (can. 499-506). Caput VI: De publicatione processus, conclusione in causa et sententia 
En la carta con que fue enviado se prescribía el uso de la lengua latina, y que el metropolitano enviase lo antes posible un ejemplar del proyecto a sus sufragáneos para que lo conocieran, debiendo reunirse con ellos para discutirlo, debiendo formularse las observaciones respectivas y enviarse todas juntas por el arzobispo a Roma. Si no era posible reunirse, que los sufragáneos enviaran por carta sus observaciones al metropolitano y, si todavía eso era difícil, que cada uno enviara sus observaciones directamente a Roma. En todo caso, las observaciones debían ser enviadas a la Santa Sede dentro de los cinco meses siguientes a su recepción.

No hay constancia de la fecha en que la carta con el proyecto fue recibida en la curia arzobispal de Santiago, pero las observaciones de los obispos chilenos fueron enviadas a Roma por carta del arzobispo González el 10 de junio de $1915^{54}$. Si tomamos en cuenta que por esas fechas se había desencadenado la primera Guerra Mundial (1914-1918) es posible que la carta llegara con algún retraso y, por lo mismo, es plausible afirmar que la respuesta fue enviada dentro del plazo estipulado por Roma. En la carta con que acompaña el informe, el arzobispo hacía presente que ni el obispo de La Serena, Ramón Ángel

(can. 507-510). Caput VII: De appellationibus (can. 511-515). Caput IX [sic = VIII]: De casibus exceptis a regulis hucusque traditis (can. 516-518). Titulus II: De causis contra sacram ordinationem (can. 519-524). Sectio III: De causis beatificationis servorum Dei et canonizationis beatorum (can. 525-528). Titulus I: De nonnullis personis quae in his processibus partem habent. Caput I: De actore et postulatore (can. 529-534). Caput II: De relatore, promotore fidei, assessore et sub-promotoribus (can. 535-539). Caput III: De notario, cancellario et patronis (can. 540-545). Titulus II: De probationibus in his processibus adhibendis. Caput I: De probationibus generatim (can. 546-549). Caput II: De testibus et peritis (can. 550-557). Caput III: De documentis processui inserendis (can. 558-562). Titulus III: De processu beatificationis servorum Dei per viam non-cultus (can. 563). Caput I: De processibus a loci Ordinario iure proprio instruendis (can. 564-568). Art. I: De processu super non cultu (can. 569-572). Art. II: De perquisitione scriptorium Servi Dei (can. 573-578). Art. III: De processu informativo (can. 579-586). Art. IV: De transmissione processus de non custu, scriptorum Servi Dei et processus informativi ad Sacram Congregationem (can. 587-589). Caput II: De processibus apostolicis. Art. I: De causae introductione apud Sacram Congregationem (can. 590-611). Art. II: De litteris remissorialibus et de processu apostolico instruendo (can. 612-625). Art. III: De iudicio super validitate processus apostolici (can. 626-628). Art. IV: De iudicio super heroicitate virtutum in specie vel super martyrio eiusque causa (can. 629-642). Art. V: De iudicio super Servi Dei miraculis in specie (can. 643-652). Titulus IV: De processu beatificationis Servorum Dei per viam cultus seu casus excepti (can. 653-663). Titulus V: De Beatorum canonizatione (can. 664-669).

52 Proyecto de libro V: Pars tertia: De processibus administrativis. Titulus I: De processibus administrativis in genere. Caput I: Quae negotia sint ordinis iudiciarii quaeque ordinis administrativi (can. 670-673). Caput II: Normae generales servandae in processibus administrativis (can. 674-682). Titulus II: De processibus administrativis in specie (can. 683). Caput I: De processu administrativo in controversies ordinis iudiciarii (can. 684690). Caput II: De processu in administrative parochorum amotione (can. 691-694). Art. I: De invitatione ad renuntiandum (can. 695-700). Art. II: De amotione decreto (can. 701-707). Art. III: De actorum revisione (can. 708-711). Art. IV: De amotione provisione (can. 712-715). Caput III: De processu administrativo in translatione parochorum (can. 716-722). Caput IV: De processu administrativo contra clericos non residents (can. 723-729). Caput V: De administrativo processu contra clericos ob turpes mores (can. 730-737). Caput VI: De processu administrativo in suspensione ex informata conscientia infligenda (can. 738-746).

53 Proyecto de libro V: Pars quarta: De processu in dimisione religiosorum (can. 747-750). Titulus I: De dimissione religiosorum qui vota solemnia aut simplicia perpetua nuncuparunt in religione clericali exempta (can. 751-767). Titulus II: De dimissione religiosorum qui vota nuncuparunt in religione clericali non exempta vel in religione laicali (can. 768-773).

${ }^{54}$ Véase su texto en anexo 2. 
Jara, ni el de Concepción, Luis Enrique Izquierdo Vargas, habían tenido observaciones que formular; y el obispo de Ancud, fray Pedro Armengol Valenzuela, O. de M., había enviado solo una observación, que se incluía en el informe; en otras palabras, siete de las ocho observaciones incluidas en el informe eran obra del arzobispo de Santiago.

El informe está manuscrito en latín, como lo pedía la carta romana, en tres folios, en los que se incluyen observaciones a ocho cánones ${ }^{55}$. Las observaciones no van numeradas, sino que cada una de ellas se inicia con el número del canon al que se hace referencia.

\section{COMPLETAR EL CANON 51 REFERIDO AL DEFENSOR DEL VÍNCULO Y AL PROMOTOR DE LA FE}

La primera observación del arzobispo es muy breve, apenas media línea, y en ella afirmaba que el canon 51 estaba trunco ${ }^{56}$. El canon observado era el primero del capítulo dedicado al promotor de justicia y al defensor del vínculo y se refería, en concreto, a la existencia del defensor del vínculo en las causas de nulidad de la ordenación y del matrimonio, y del promotor de la fe en las causas de beatificación y canonización ${ }^{57}$.

En un diccionario de derecho canónico de la época ${ }^{58}$, se precisaba que la existencia de promotores era antigua en la Iglesia y que "fueron instituidos para que hiciesen todas las demandas relativas al orden e interés público; para mantener los derechos, libertades e inmunidades de la Iglesia, conservar la disciplina eclesiástica e informar contra los clérigos de malas costumbres para que se les corrigiese"; la figura del defensor de justicia fue establecida por Benedicto XIII (1724-1730) para toda la Iglesia, mediante un quirógrafo de su primer año de pontificado. Por su parte, Donoso ${ }^{59}$, citando la constitución Dei miseratione de Benedicto XIV, de 3 de noviembre de 1741, ponía de relieve que en cada diócesis el obispo debía elegir "un individuo de probidad y pericia en el derecho eclesiástico, siempre que se pueda, el cual con el nombre de defensor de matrimonio... siendo su deber, defender la validez del matrimonio, de palabra y por escrito, y hacer, a este respecto, todas las observaciones que crea conducentes"; a él le correspondía apelar de la sentencia en que se declaraba nulo el matrimonio, aunque ninguna de las partes hubiese interpuesto el recurso. Este autor, empero, no se refería a

\footnotetext{
55 Véase su texto en anexo 3.

56 Animadversiones [1]: "Can. 51. Hic canon est truncus".

57 Proyecto de libro V: De iudiciis ecclesiasticis; Pars prima: De Iudiciis Ecclesiasticis in genere; Sectio I: De Tribunalium ecclesiasticorum ordinatione; Titulus II: De tribunali ordinario primae instantiae; Caput III: De Promotore iustitiae, ac vinculi Defensore; canon 51: "Pro causis criminalibus tum etiam contensiosis in quibus bonum publicum in discrimen vocari potest vel quoties alicuius contumacia per poenam fragenda est, constiquibus agitur de vinculo sacrae ordinationis, aut matrimonii, vinculi defensor; in causis beatificationis Servorum Dei et canonizationes Beatorum, promotor fidei" = "Para las causas criminales y también en las contenciosas en las que el bien público puede estar en peligro o cuantas veces la contumacia de alguno debe ser rota por una pena, constitúyase un defensor del vínculo para aquellas en que se trate del vínculo de la sagrada ordenación, o del matrimonio; un promotor de la fe en las causas de beatificación de los siervos de Dios y de canonización de los beatos".

58 Diccionario (1859) pp. 970-971.

${ }^{59}$ Donoso (1849) p. 349.
} 
los juicios de nulidad de la sagrada ordenación ni mencionaba, por lo mismo, al defensor del vínculo en este tipo de juicios, pero, en cambio, hacía expresa referencia al juicio en que se demandaba la nulidad de la profesión religiosa ${ }^{60}$, en el que había intervención, en todos los actos del juicio, del defensor de profesiones que los obispos debían nombrar en sus diócesis, nombramiento que debía recaer en un eclesiástico secular o regular, de probidad e instrucción, al igual que el defensor del vínculo matrimonial ${ }^{61}$. En las causas de beatificación y de canonización existía, igualmente, la figura del promotor, pero su función era la defensa del derecho y del interés público de la Iglesia de manera que no alcanzase el honor de los altares quien no era digno de él.

Puesto que se trataba del primer canon del capítulo referido a las figuras del promotor de justicia y del defensor del vínculo, parecía lógico se que se refiriera a ambas, y el inicio del canon parece indicar que así se pretendía, pues se hacía referencia a los juicios penales en los que tenía cabida la intervención del promotor de justicia y no del defensor del vínculo; pero la redacción final del mismo solo hizo referencia al defensor del vínculo y al promotor de la fe.

La observación era exacta y, de hecho, ella aparece rayada en el informe, señal de que fue considerada relevante por el cardenal Gasparri. La redacción final del canon, que pasó a ser el canon 1586 del Codex ${ }^{62}$, corrigió el error, pues, no solo aparecen mencionadas ambas figuras, el promotor de justicia y el defensor del vínculo, sino que, además, se eliminó la referencia al promotor de la fe en las causas de beatificación y canonización, que ocupó un lugar especial en otra parte del código en que se trataba específicamente De las causas de beatificación de los Siervos de Dios y de canonización de los beatos ${ }^{63}$.

\section{INCLUIR A LOS OBISPOS EN EL PRIVILEGIO DE SER TOMADOS SUS TESTIMONIOS EN SU CASA}

La segunda observación, cuyo origen está en la sugerencia hecha por el obispo de Ancud, fray Pedro Armengol Valenzuela, O. de M., decía relación con el canon 258 del proyecto ${ }^{64}$, referido al privilegio de reyes y autoridades supremas de una nación de dar su testimonio en su casa, privilegio que el mismo canon en su parágrafo 2 hacía extensivo a los cardenales ${ }^{65}$. Según

\footnotetext{
${ }^{60}$ Donoso (1849) pp. 353-355.

${ }^{61}$ Benedicto XIV, constitución Si datam hominibus, cit. ibíd.

62 CIC 1917, canon 1586: "Constitúyase en cada diócesis el 'promotor de justicia' y el 'defensor del vinculo': aquel, para las causas contenciosas, en que, a juicio del Ordinario, corre peligro el bien público, y para las criminales; este, para aquellas en que se trate del vinculo de la sagrada ordenación del matrimonio".

63 CIC 1917, canon 2010-2012.

64 Proyecto de libro V; Pars prima, De Iudiciis Ecclesiasticis in genere; Sectio II: De processu judiciario generatim; Titulus X: De testibus et attestationibus; caput III: De citatione testium.

65 Proyecto de libro V, canon 258: "\$ $\$$. Reges, iique, qui supremam in civili societate potestatem obtinent, non sunt citationibus ad testificandum evocandi sed, si postulentur testes, et iudex eorum testimonium necessarium ducat, eos rogabit ut auditores et notarium benigne domi recipere dignentur, excepturos eorum testificactiones, actis causae inserendas. $\$ 2$. Eodem privilegio fruuntur $S$. R. E. Patres Cardinales" $=$ " 1 . Los reyes y aquellos que obtienen el poder supremo en la sociedad civil, no deben ser llamados por citaciones para testificar, pero si se postulan como testigos, y el juez considera necesario su testimonio, les solicitará que reciban benignamente en su casa al auditor y al notario, para que recojan su testimonio y los incorporen a las actas de la causa. $\$ 2$. Gozan de este mismo privilegio los $S$. R. E. padres cardenales”.
} 
el obispo de Ancud ${ }^{66}$, debía agregarse en el parágrafo 2 la frase "y también los obispos", para que el referido canon 258 estuviera en concordancia con el canon $266 \mathrm{n}^{\circ} 1^{67}$.

El canon 258 al que hacía referencia esta segunda observación chilena, estaba situado en el capítulo III dedicado a la citación de los testigos, el que estaba integrado por cuatro cánones (can. 255-258), siendo el canon 258 el último de los cuatro. Pues bien, el capítulo III fue eliminado y no se incorporó como tal en el código finalmente aprobado; pero de los cuatro cánones que lo integraban, los dos primeros pasaron al Codex en tanto que los dos últimos, incluido el canon 258, fueron simplemente eliminados. A decir verdad, a la luz de lo afirmado por el canon $266 \mathrm{n}^{\circ} 1$ del proyecto, el canon 258 parecía una redundancia, pues su contenido específico quedaba incluido en los términos genéricos en los que estaba redactado aquel. Es por lo que el canon $266 \mathrm{n}^{\circ} 1$ del proyecto pasó al código, ahora como canon $1770^{68}$.

La sugerencia del obispos ancuditano no aparece tarjada en el informe revisado en Roma por lo que, en opinión del cardenal Gasparri, no era mayormente relevante, lo que parece claro, sobre todo, si se estaba decidiendo la eliminación del canon 258.

\section{NULIDAD DE LA SENTENCIA POR CARECER DE FUNDAMENTOS}

La tercera observación está referida al canon $390 \mathrm{n}^{\circ} 3$ del proyecto ${ }^{69}$ que era el primero de los cánones que integraban el título en que se regulaba la querella de nulidad; en él se establecía que la sentencia adolecía del vicio de nulidad, entre otras razones, cuando carecía de los motivos o razones del fallo ${ }^{70}$, circunstancia esta que atraía la atención del arzobispo. Según él, era preciso que se entendiera que las sentencias, en relación con esta materia, no eran válidas a menos que en ellas se expresaran las razones o los fundamentos de lo sentenciado ${ }^{71}$.

La querella de nulidad era un recurso establecido contra las sentencias nulas, es decir, aquellas que, careciendo de valor legal, tenían, sin embargo, alguna apariencia de

${ }^{66}$ Animadversiones [2]: “Can. 258: Eodem privilegio fruuntur Patres Cardinales', addatur: 'atque Episcopi” ut cohaereat cum canone $266 n^{\circ} 1$ (Epus. Ancuditanus)".

67 Proyecto de libro V, canon 266: "Testes sunt examini subiiciendi in ipsa tribunales sede. Excipiuntur: $1^{\circ}$ Episcopi et personas illustres quae suae civitatis iure eximuntur ab obligatione comparendi coram iudice testificando causa, qui omnes eligere ipsi possunt locum ubi testificentur, de quo iudicem qui eos citavit certiorem facere debent" = "Los testigos han de ser examinados en la sede misma del tribunal. Están exceptuados: $1^{\circ}$ Los obispos y personas ilustres que por el derecho de su nación están exentos de la obligación de comparecer ante el juez para testificar, todos los cuales pueden elegir lugar para hacerlo y deben notificárselo al juez que los citó".

${ }^{68}$ CIC 1917, canon 1770: "\$ 1. Los testigos han de ser examinados en la sede misma del tribunal. $\$ 2$. Están exceptuados de esta regla general: $1^{\circ}$ Los Cardenales de la Santa Iglesia Romana, los Obispos y personas ilustres que por el derecho de su nación están exentas de la obligación de comparecer ante el juez para testificar: todos estos pueden elegir lugar para hacerlo y deben notificárselo al juez".

${ }_{69}$ Proyecto de libro V; Pars prima: De Iudiciis Ecclesiasticis in genere; Sectio II: De processu judiciario generatim; Titulus XIX: De querela nullitatis adversus sententiam.

70 Proyecto de libro V, canon 390: "Sentencia vitio nullitatis laborat quando: $3^{\circ}$ Motivis seu rationibus decidendi est destituta" = "La sentencia adolece del vicio de nulidad cuando: $3^{\circ}$ No se alegan los motivos o razones del fallo".

${ }^{71}$ Animadversiones [3]: "Can. $390 n^{\circ}$ 3: Oportet ut rite exprimatur hoc, nempe: utrum eae sententiae sint validae necne, in quibus earumdem non exponantur rationes, seu fundamenta". 
validez. Tres cánones del proyecto regulaban esta querella (can. 390-392) la que, conforme al canon 390, procedía en cinco circunstancias diversas, la tercera de las cuales era la falta de motivación de la misma ${ }^{72}$.

La observación del arzobispo González no era una sugerencia de reforma de la norma, sino de inteligibilidad de la misma, y aparece tarjada en el original del informe enviado a Roma; es decir, fue una sugerencia tomada en cuenta, no obstante que el texto de la específica causal observada permaneció inalterado en el código de 1917, si bien cambió de ubicación. En realidad, la regulación de la querella de nulidad en el Codex difirió notablemente de la contemplada en el proyecto de 1915, porque en este no se hacía la distinción que se hizo finalmente en el Codex, entre querella de nulidad sanable e insanable, siendo la razón de dicha distinción la mayor o menor gravedad del defecto que hacía nula la sentencia ${ }^{73}$. En el código se recogieron algunas de las causas que en el proyecto anulaban la sentencia y se distribuyeron entre ambas modalidades de querella de nulidad, siendo la tercera, es decir, la que merecía las observaciones del arzobispo, incorporada entre las causales que daban origen a una nulidad sanable ${ }^{74}$. Se hizo, sin embargo, con una breve añadido al final de la norma, añadido que no estaba en el proyecto, y que es una salvedad que se hace en relación con el canon 1605 en el que se estableció que "las sentencias del Supremo Tribunal de la Signatura son válidas aunque no expresen ni las razones de hecho ni las de derecho".

\section{TRIBUNAL PARA CONOCER UNA SEGUNDA APELACIÓN}

La cuarta observación se hacía al canon 417 en relación con los cánones 67 y 72 $\mathrm{n}^{\circ} 3$ del proyecto. Es la más larga de las observaciones hecha por los obispos chilenos durante todo el proceso codificador. Disponía el canon 417 del proyecto ${ }^{75}$ las razones que permitían alcanzar la cosa juzgada ${ }^{76}$, en tanto que el canon 67 era el primero de los

\footnotetext{
${ }^{72}$ Las otras causales eran: $1^{\circ}$ haber sido dictada por un juez incompetente o por un tribunal colegiado no integrado por el número legítimo de jueces; $2^{\circ}$ la parte dispositiva de la sentencia se basa en un evidente error de derecho o de hecho, como un documento que posteriormente es declarado falso; $4^{\circ}$ carece de las firmas necesarias; $5^{\circ}$ defecto de citación o ausencia del juicio del promotor de justicia o del defensor del vínculo, si ellos debieron intervenir por prescripción del derecho, o por defecto de legitimación para estar en juicio.

73 Alonso y Cabreros (1964), p. 632.

${ }^{74}$ CIC 1917, canon $1894 \mathrm{n}^{\circ}$ 2. Tomadas del proyecto se incluyeron, además, como causales de nulidad sanable, la falta de legítima citación $\left(n^{\circ} 1\right)$ y la carencia de firmas prescritas por el derecho $\left(n^{\circ} 3\right)$. En cambio, el canon 1892 recogió del proyecto, entre las causales de nulidad insanable, el que la sentencia fuese dada por un juez absolutamente incompetente o en tribunal colegiado integrado por número ilegítimo de jueces $\left(n^{\circ} 1\right)$ o fuese dada entre partes de las que al menos una carecía de personalidad para comparecer en juicio" $\left(n^{\circ} 2\right)$.

75 Proyecto de libro V: Pars prima: De Iudicii Ecclesiasticis in genere; Sectio II: De processu judiciario generatim; Titulus XXII: De re iudicata.

76 Proyecto de libro V, canon 417: "Res iudicata habetur: $1^{\circ}$ Duplici sentencia conformi; $2^{\circ}$ Decreto, quo appellatio, a parte interposita, a iudice seu a tribunali appellationis ut futilis vel vexatoria repulsa sit; $3^{\circ}$ Sentencia intra utile tempos non appellata; aut quae, licet appellata coram iudice a quo, deserta fuit coram iudice ad quem; $4^{\circ}$ Sentencia unica, si pars in scriptis expresse appellatione renuntiaverit, vel sententia iureiurando litis decisorio innitatur, vel lata sit in causis pro quibus ius cavet expeditissime et adpellatione [sic] remota rem esse definiendan aut contra contumacem qui, serius interveniens, se a sua contumacia purgare non
} 
dos cánones ${ }^{77}$ en los que se regulaba el tribunal ordinario de segunda instancia ${ }^{78}$. Por su parte, el canon 72 enumeraba las causa que podía conocer el tribunal de la Sagrada Rota Romana $^{79}$, la tercera de las cuales disponía que dicho tribunal romano conocía en última instancia de las causas que los ordinarios y otros tribunales hubiesen conocido en segunda o en ulterior instancia, que no habiesen alcanzado la fuerza de cosa juzgada, si eran deferidas a la Santa Sede por legítima apelación ${ }^{80}$.

valuit" = "Hay cosa juzgada: $1^{\circ}$ Habiendo dos sentencias conformes; $2^{\circ}$ Tratándose de un decreto, cuando la apelación, interpuesta por una de las partes, ha sido rechazada por el juez o por el tribunal de apelación por fútil o vejatoria; $3^{\circ} \mathrm{Si}$ no se apeló de la sentencia dentro del tiempo útil, o si, habiéndose apelado ante el juez a quo, se abandonó ante el juez ad quem; $4^{\circ}$ Tratándose de sentencia única, si la parte por escrito ha renunciado expresamente a la apelación, o la sentencia se basa en el juramento decisorio del proceso, o sea dada en causa para la cual el derecho ordena resolver con suma rapidez o contra el contumaz que, interviniendo con seriedad, no depone su contumacia".

77 Proyecto de libro V; Pars prima: De Iudiciis Ecclesiasticis in genere; Sectio I: De Tribunalium ecclesiasticorum ordinatione; Titulus III: De tribunali ordinario secundae instantiae.

78 Proyecto de libro V, canon 67: "\$1. A tribunali Episcopi suffraganei appellatur ad Metropolitam. $\$ 2 . A$ causis in prima instantia pertractatis coram Metropolita erit appellatio ad alium Metropolitam vel Espiscopum, quem ipse Metropolita, probante Sede Apostolica, infra annum a publicatione huius Codicis designaverit. $\$ 3$. Pro causis primum agitatis coram Archiepiscopoqui caret suffraganeis vel coram Ordinario immediate Sedi Apostolicae subiecto, erit appellatio ad Archiepuscopum, de quo in can. 168, De personis. $\$ 4$. Inter religiosos exemptos pro omnibus causis coram superiore provinciali actis tribunal secundae instantiae est penes supremum moderatorem, pro causis actis coram abbate locali, penes abbatem generalem, si monasterium ad aliquam congregationem pertinet, secus penes Sanctam Sedem. Appellationes autem religiosorum in alienis tribunalibus non recipiantur, nisi causa iam a supremo eorum moderatore cognita fuerit, salvo praescripto can. $15 "=" \$ 1$. Del tribunal de un Obispo sufragáneo se apela al Metropolitano. $\$ 2$. De las causas tratadas en primera instancia ante el Metropolitano se apelará ante otro Metropolitano u Obispo, que el mismo Metropolitano, con aprobación de la Sede Apostólica designará dentro del año de publicación de este código. $\$ 3$. De las causas discutidas en primera instancia ante el Arzobispo que carece de sufragáneos o ante un Ordinario inmediatamente sujeto a la Sede Apostólica, se apelará al Arzobispo de que se trata en el canon 168 del libro De las personas. $\$ 4$. Los religiosos exentos, para todas las causas tratadas ante el superior provincial tienen como tribunal de segunda instancia el del superior general; para las causas tratadas ante el abad local, el del abad general; si el monasterio pertenece a otra congregación, la Santa Sede. Ahora bien, las apelaciones de los religiosos no sean recibidas en otros tribunales, a no ser que la causa haya sido conocida por el superior general, salvo lo prescrito en el canon 15". La referencia al canon 168 del libro II, acerca de las personas, está mal hecha porque este canon se refiere a la expiración del nombramiento de los legados pontificios; debió hacerse al canon 184 que establecía que los obispos que no se hallasen bajo ningún metropolitano, los abades o prelados nullius y los arzobispos que carecían de sufragáneos, si aún no lo habían hecho, debían elegir de una vez para siempre, con la aprobación previa de la Sede Apostólica, algún metropolitano de los más vecinos a cuyo concilio provincial debían asistir. En cuanto al canon 15 del proyecto, disponía que por razón del primado del Romano Pontífice, podía cualquier fiel en todo el orbe católico llevar o introducir una causa para que la juzgase, fuese contenciosa o criminal, en cualquier grado del juicio y cualquiera fuese el estado del pleito $(\$ 1)$. Este recurso, sin embargo, no suspendía el ejercicio de la jurisdicción del juez que había empezado a conocer de la causa, el que podía proseguir el juicio hasta la sentencia definitiva a menos que, por documento cierto, constase que la Santa Sede prohibía la prosecución de las actuaciones procesales y se avocaba la causa $(\$ 2)$.

${ }^{79}$ Proyecto de libro V; Pars prima: De Iudiciis Ecclesiasticis in genere; Sectio I: De Tribunalium ecclesiasticorum ordinatione; Titulus IV: De Apostolicae Sedis tribunalibus; Caput I: De Sacra Rota Romana.

${ }^{80}$ Proyecto de libro V, canon 72: " $\$ 1$. Sacra Rota iudicat: $3^{\circ}$ in ultima instantia causas ab Ordinariis et ab aliis quibusvis tribunalibus in secunda vel ulteriori instantia iam cognitas, quae in rem iudicatam non transierint, si per legitimam appellationem ad Sanctam Sedem deferuntut". 
Sostenía el arzobispo González que, de acuerdo con el canon 67, de la sentencia del obispo se apelaba ante el metropolitano; sin embargo, de la sentencia del metropolitano dada en primera instancia se apelaba ante otro ordinario, ya metropolitano u obispo, esto es, ante el prelado que el mismo metropolitano hubiese constituido en juez de apelación dentro del año de publicación del código, con la aprobación de la Santa Sede. Del mismo modo, conforme al canon 417, dos sentencias conformes alcanzaban cosa juzgada; y de acuerdo con el canon 72 número 3 la Sagrada Rota juzgaba definitivamente de las sentencias dictadas por cualquier tribunal en segunda o ulterior instancia, de las que se hubiese apelado legítimamente ante la Santa Sede. A la luz de dichos supuestos, proponía el siguiente caso: el obispo o el arzobispo dicta sentencia en primera instancia, la que es revocada por el juez de apelación; los litigantes desean apelar, pero de ningún modo desea hacerlo a la Rota Romana porque los gastos serían demasiados onerosos puesto que están lejos de la urbe. Preguntaba, entonces, el arzobispo, ante qué tribunal se podía acudir, porque conforme al canon 67, no se podía apelar sino ante otro metropolitano; o había que apelar a la Rota Romana, o quizá debían consentir en que la sentencia pasase a cosa juzgada. De acuerdo con el proyecto, parecía al arzobispo que la solución, de acuerdo con el canon 67, era que de cualquier sentencia dictada por un metropolitano en primera o en segunda instancia se podía apelar ante el juez ordinario constituido por el metropolitano para ello, salvo el derecho de la Rota Romana ante la que se podía apelar de cualquier sentencia dada en segunda instancia ${ }^{81}$.

La duda del arzobispo estaba claramente planteada y, a decir verdad, de la lectura de los cánones que él mencionaba surgía una respuesta clara a la misma, pues la duda se dirigía a identificar el tribunal que debía juzgar, en tercera instancia, una causa sentenciada en segunda instancia y ello estaba claramente resuelto en el canon $72 \mathrm{n}^{\circ} 3$ del proyecto que el mismo arzobispo citaba, según el cual, correspondía a la Rota Romana conocer en última instancia de las causas conocidas en segunda o ulterior instancia por los ordinarios u otros tribunales, que no hubiesen pasado aún a cosa juzgada. En el fondo, el problema planteado por el metropolitano chileno era más bien un problema de costos, pues la tramitación de cualquier causa en Roma resultaba muy onerosa. Era lo que le llevaba a una interpretación forzada que no tenía mayor respaldo en los proyectos de cánones.

Puesto que se trataba de una duda, no tuvo mayor efecto, más aún si la respuesta a la misma era proporcionada por el proyecto; de hecho, ella no aparece tarjada en el original manejado por el cardenal Gasparri. Y la interpretación que hacía del canon 67 tampoco tuvo acogida en el código una vez promulgado. En efecto, el canon 67 del proyecto se transformó, con algunos cambios menores, en el canon 1594 del Codex ${ }^{82}$,

\footnotetext{
81 Véase su texto en anexo 3.

82 CIC 1917, canon 1594: “\$1. Del tribunal de un Obispo sufragáneo se apela al Metropolitano. $\$ 2$. De las causas tratadas en primera instancia ante el Metropolitano se apela al ordinario local que de una vez para siempre el mismo Metropolitano haya designado con aprobación de la Sede Apostólica. $\$ 3$. De las causas discutidas en primera instancia ante el Arzobispo que carece de sufragáneos o ante un Ordinario local inmediatamente sujeto a la Sede Apostólica, se apela al Metropolitano, del que se habla en el canon 285. $\$$ 4. Los religiosos exentos, para todas las causas tratadas ante el Superior provincial, tienen como tribunal de segunda instancia el del Superior general; para las causas tratadas ante el Abad local, el del Superior supremo de la Congregación monástica; más para las causas de que trata el canon 1579 , $\$ 3$, se observará lo prescrito en los párrafos 1,2 y 3 de este canon”.
} 
pero se siguió hablando de sentencias dictadas en primera instancia. Y el canon $72 \mathrm{n}^{\circ} 3$ del proyecto, pasó a ser el canon 1599 n 2 según el cual la Rota conocería "en última instancia, las causas ya falladas en segunda o ulterior instancia por la misma S. Rota o por otros tribunales y que no hayan pasado a ser cosa juzgada".

\section{CORREGIR UNA REMISIÓN A UN CANON EQUIVOCADO EN MATERIA DE PROCESOS MATRIMONIALES}

La quinta observación del arzobispo de Santiago se refirió al canon 517 del proyecto $^{83}$, el segundo de los tres cánones que integraban el capítulo dedicado a los casos en que se podía declarar la nulidad del matrimonio sin seguir las reglas que se habían dado en los cánones anteriores acerca del proceso de nulidad del matrimonio ${ }^{84}$. Pedía el arzobispo ${ }^{85}$ que la referencia que el canon 517 hacía al canon $518^{86}$ fuera hecha al canon $516^{87}$.

La observación era tan solo formal, pues no entraba en el contenido sustantivo de los cánones, pero era una observación correcta, al punto que aparece tarjada en el original, es decir, fue tomada en consideración por el cardenal Gasparri. De hecho, la remisión se hizo correctamente en el código cuando el canon 1991, que recogía el canon 517 del proyecto, se refirió al canon 1990 del Codex que fue el canon que recogió, casi en los mismos términos, el canon 516 del proyecto.

83 Proyecto de libro V, canon 517: "Adversus hanc declarationem vinculi Defensor, si prudenter existimaverit impedimenta de quibus in can. 518 non esse certa aut dispensationem super eisdem probabilem esse, provocare tenetur, et acta processus ad superius tribunal sunt transmittenda, cum adnotatione, quod agitur de casu excepto" = "Contra esta declaración, si el defensor del vínculo juzga prudentemente que los impedimentos mencionados en el canon 518 no son ciertos o que es probable que haya dispensa de ellos, tiene obligación de enviar al tribunal superior las actas del proceso, con anotación de que se trata de un caso exceptuado".

84 Proyecto de libro V: Pars altera: De iis quae in nonnullis iudiciis ecclesiasticis servando sunt; Sectio II: De causis matrimonialibus et contra sacram ordinationem; Titulus I: De causis matrimonialibus; Caput VIII: De casibus exceptis a regulis hucusque traditis.

85 Animadversiones [5]: "Can. 517. Afferatur can 516 pro can. 518" = "Añadir el canon 516 en vez del canon 518".

86 Proyecto de libro V, canon 518: "\$ 1 . Superius tribunal, cum solo intervente Defensoris vinculi decernet eodem modo de quo in can. 516 , utrum sentencia sit conformanda, an potius infirmanda. $\$ 2$. Interim partes a novis contrahendis nuptiis prohibitae manent" $=" \$ 1$. El tribunal superior, con la sola intervención del defensor del vínculo, decretará en la misma forma expresada en el canon 516, si se ha de confirmar la sentencia, o bien anularla. $\$ 2$. Entretanto, se prohíbe a las partes contraer nuevas nupcias".

87 Proyecto de libro V, cano 516: "Quum ex certo et authentico documento, quod nulli contradictioni vel exceptioni obnoxium sit, constiterit de existentia impedimenti disparitatis cultus, ordinis, voti solemnes castitatis, ligaminis, consanguineitatis, affinitatis ex copula licita aut cognationis spiritualis, simulque pari certitudine apparuerit dispensationem super his impedimentis datam non esse, hisce in casibus, praetermissis solemnitatibus hucusque recensitis, poterit tribunal matrimonii nullitatem declarare, cum intervente tamen Defensoris vinculi" = "Cuando por un documento cierto y auténtico que no admite contradicción ni excepción de ninguna clase consta de la existencia del impedimento de disparidad de cultos, orden, voto solemne de castidad, ligamen, consanguinidad, afinidad por cópula lícita o parentesco espiritual, y cuando a la vez se sabe con igual certeza que no se ha concedido dispensa de estos impedimentos, puede en estos casos el tribunal declarar la nulidad del matrimonio sin sujetarse a las solemnidades hasta ahora mencionadas, pero interviniendo el defensor del vínculo". 


\section{EFECTO DEVOLUTIVO DE LA APELACIÓN JUDICIAL INTERPUESTA CONTRA DECRETO ADMINISTRATIVO}

Esta observación del arzobispo de Santiago se hacía al parágrafo $1^{\circ}$ del canon 682 del proyecto ${ }^{88}$, el último de los nueve cánones que contenían las normas generales que debían observarse en los procesos administrativos ${ }^{89}$. Disponía este canon que por un decreto administrativo se daba recurso en devolutivo solo ante la Sede Apostólica, dentro de los diez días contados desde que la parte había hecho la denuncia, salvas dos excepciones en que el recurso se daba para ante el ordinario; pero si alguien consideraba que el decreto había violado un peculiar derecho propio, podía pedir que esta materia se definiese en sede judicial, en cuyo caso el juez que conocería de la misma sería el juez de apelación si hubiese empezado a tratarse por vía judicial.

El arzobispo consideraba que era conveniente que la apelación concedida en la segunda situación, esto es, cuando el asunto administrativo empezaba a ser conocido en sede judicial, tuviese solo efecto devolutivo, porque esta apelación no tendría otra finalidad que ser un recurso dilatorio para que ninguno fuese suspendido del beneficio ${ }^{90}$.

Fue una observación que no tuvo mayor acogida; de hecho, no está tarjada en el original, señal de que, si bien fue conocida, no fue mayormente considerada. Y la razón parece clara, porque esta fue una de las materias que sufrió cambios sustanciales en el código. En efecto, en el Codex desapareció todo el título primero de la parte tercera del libro $\mathrm{V}$, parte que se refería a los procesos administrativos, cuyo título primero trataba de dichos procesos en general, sede en la que se encontraba el canon 682 observado por el metropolitano santiaguino. Eliminado el título respectivo, y con ello el canon observado, no cabía tomar en cuenta la observación ${ }^{91}$.

Parece, sin embargo, que la observación tampoco habría sido considerada de haber permanecido el canon, porque la siguiente de sus observaciones, como veremos de inmediato, aparece tarjada en el original por el cardenal Gasparri, aunque el canon respectivo también desapareció en la edición final del Codex.

\footnotetext{
88 Proyecto de libro V, canon 682: "\$ 1. Ab administrativo decreto intra decem dies a denuntiatione partibus facta datur recursus in devolutivo tantum ad Seden Apostolicam, salvo praescripto can. 690 et can. 708; sed si quis ex eodem decreto peculiare ius suum violatum putet, poterit ad eum Superior rem deferre judiciario ordine definiendam; qui de eadem re ut iudex appellationis cognosceret si judiciaria ratione tractari coepta esset". El canon 690 y el canon 708 establecían un recurso administrativo contra un decreto administrativo para ante el ordinario.

${ }^{89}$ Proyecto de libro V; Pars tertia: De processibus administrativis; Titulus I: De processibus administrativis in genere; Caput II: Normae generales servandae in processibus administrativis.

${ }^{90}$ Animadversiones [6]: “Can. 682 S 1. Exprimi oportet quod appellatio eo inciso concesa, quod incipit: 'Sed si quis ex eodem decreto peculiare jus suum violatum putet, etc.', vim habeat tantum quod effectum devolutivum; secus ipsa appellatio nibil aliud esset quam recursos dilatorius, ne quis a beneficio suspenderetur".

${ }^{91}$ El libro V del proyecto pasó a ser el libro IV del Codex y en este, la tercera parte llevó el siguiente título: "Del modo de proceder en la tramitación de algunos asuntos y en la aplicación de algunas sanciones", la que se dividía en siete títulos dedicados cada uno de ellos a diversos procedimientos en particular.
} 


\section{CORREGIR UNA REMISIÓN EQUIVOCADA A UN CANON EN MATERIA DE PROCESOS ADMINISTRATIVOS EN CONTROVERSIA DE ORDEN JUDICIAL}

La penúltima observación del arzobispo de Santiago se refería al canon 684 del proyecto y era una observación meramente formal, pues sugería corregir una cita equivocada a un canon y proponía que la cita se hiciese al canon correcto. El canon 684 era el primero de los siete cánones que integraban el capítulo referido al proceso administrativo en controversias del orden judicial ${ }^{92}$ y disponía en su parágrafo primero ${ }^{93}$ que, si una causa de orden judicial sería dirimida por trámite administrativo por el consentimiento de las partes, según disponía el canon 679 del proyecto, las partes debía exponer su intención al ordinario por escrito con todos los argumentos de hecho y de derecho en la que la misma se sustentaba.

El canon 679 citado, sin embargo, refiriéndose a otra materia, disponía ${ }^{94}$ que los examinadores y consultores, previo juramento, debían, sub gravi, guardar secreto acerca de todo lo que conocieran con ocasión de sus oficios, especialmente tratándose de documentos reservados, los debates habidos en los consejos, el número de los sufragios y sus razones $(\$ 1)$, de manera que, si no lo cumplían, no solo serían removidos, sino que podrían ser sancionados por el ordinario y obligados a resarcir los daños ocasionados $(\mathbb{S}$ 2). Era, pues, una remisión equivocada, pues el canon que debía citarse correctamente era el canon 671 del proyecto ${ }^{95}$, según el cual las controversias de orden judicial podían las partes de común acuerdo y con el consentimiento del superior dirimirlas por vía administrativa, con tal de que el negocio fuera de aquellos que podían transigir o someter al compromiso de árbitros según la norma del canon 8.

Es por lo que el arzobispo sugería ${ }^{96}$ que la cita que en el canon 684 del proyecto se hacía al canon 679 se sustituyera por la del canon 671. Se trató de una observación correcta y por eso aparece tarjada en el original, según la práctica del cardenal Gasparri de tarjar las observaciones que consideraba adecuadas y que tomaba en cuenta para corregir los proyectos. Pero, en definitiva, no tuvo mayores consecuencias, porque el canon 684 se encontraba situado entre los siete cánones que regulaban los procesos administrativos en las controversias judiciales, todos los cuales desaparecieron del texto final del código.

\footnotetext{
92 Proyecto de libro V; Pars tertia: De processibus administrativis; Titulus II: De processibus administrativis in specie; Caput I: De processu administrativo in controversias ordinis iudiciarii.

93 Proyecto de libro V, canon 684: "\$ 1. Si causa ordinis iudiciarii administrativo tramite ex partium consenso sit dirimenda ad normam can. 679, pars recurrens intentionem vel querelam suam scriptis cum omnibus facti adiunctis et iuris rationibus quibus ipsa fulcitur, exponat Ordinario. \$2. Ordinarius sacerdotem idoneum ad controversiam dirimendam deleget".

94 Proyecto de libro V, canon 679: "\$ 1. Examinatores et consultores debent sub gravi, interposito iureiurando, servare secretum circa omnia quae ratione sui muneris noverint ac praesertim circa documenta occulta, disceptationes in concilio habitas, suffragiorum numerum ac rationes. $\$ 2$. Si huic praescriptio minime paruerint, non solum a munere examinatoris et consultoris amovendi erunt, sed alia etiam condigna poena ab Ordinario, servatis servandis, plecti poterunt; ac praeterea damna, si qua inde sequita fuerint, sarcire tenebuntur".

95 Proyecto de libro V, canon 671: "Controversiae ordinis iudiciarii possunt utraque parte consentiente et annuente Superiore, dirimi via administrativa, dummodo tamen negotium tale sit in quo partes valeant transigere aut in arbitros compromittere ad normam can. 8".

96 Animadveriones [7]: “Can. 684. Afferatur can. 671 pro can. 679”.
} 


\section{PRIVACIÓN DE BENEFICIO A LOS CLÉRIGOS DE MALAS COSTUMBRES}

Según el texto del informe del arzobispo de Santiago, la última de sus observaciones se refería al canon $753 \mathrm{n}^{\circ} 3$, pero se trata de un error evidente, pues la observación hay que entenderla hecha al canon $735 \mathrm{n}^{\circ} 3$ de dicho proyecto. Por de pronto, el canon 753, que es el mencionado en el informe, consta solo de un parágrafo el que no contiene ninguna numeración ${ }^{97}$. Pero es el mismo texto de la observación episcopal el que proporciona los datos necesarios para identificar con facilidad el canon correcto, toda vez que transcribe una frase del canon observado que el arzobispo sugiere sustituir por otra que él mismo propone.

El canon 735 se situaba entre los cánones que regulaban el proceso administrativo contra los clérigos de malas costumbres ${ }^{98}$ y, en concreto, regulaba las consecuencias que tenía para el clérigo el que sus excusas no se considerasen legítimas. Disponían los cánones de este capítulo que el clérigo que tenía consigo mujer sospechosa o que frecuentase su trato, debía ser amonestado para que la despidiera o se abstuviera de frecuentarla. Podía, sin embargo, el clérigo en cuestión alegar excusas, acerca de las cuales el obispo debía oír a dos examinadores sinodales, hecho lo cual, si el obispo no las consideraba legítimas, el clérigo debía cumplir lo mandado dentro de un término prudencial, de manera que, de no hacerlo, se seguían las consecuencias que enumeraba el canon 735 que era el observado por el obispo chileno en su número 3. Según este ${ }^{99}$, si el clérigo estaba en posesión de un beneficio amovible, debía ser suspendido; y en el decreto de suspensión se había de expresar que, si el clérigo no obedecía el decreto dentro del mes, el beneficio vacaría de inmediato; si el mes pasaba en vano, el obispo debía declarar vacante el beneficio.

La observación del prelado chileno ${ }^{100}$ pedía sustituir la condición de beneficio amovible del que estaba en posesión el clérigo amonestado, por la de beneficio inamovible. Se trataba de una reforma sustantiva que fue tomada en cuenta por los codificadores. Aparte del hecho formal de que esta observación aparece tarjada en el original que manejó el cardenal Gasparri, el texto final del Codex no distinguió si se trataba de beneficios amovibles o inamovibles, sino que dio un trato único, cuando se trataba de beneficios sin cura de almas distintos de la parroquia, en cuyo caso, si el clérigo no

\footnotetext{
${ }_{97}$ Proyecto de libro V, canon 753: "Abbas aut Superior mayor cum consenso aliorum qui una cum ipso tribunal constituunt, Promotores iustitiae nominet ad normam can 52" = "El abad o el superior mayor con el consentimiento de los otros que constituyen tribunal con él, nombrará al promotor de justicia según la norma del canon 52".

98 Proyecto de libro V; Pars tertia: De processibus administrativis; Titulus II: De processibus administrativis in specie; Caput V: De processu administrativo contra clericos ob turpes mores.

99 Proyecto de libro V, canon 735: "\$ 1 . Si ne eas quidem Ordinarius habeas legitimas, clerico rursus praecipiat ut infra congruum tempos mandato obtemperet; qtempore inutiliter transacto: $3^{\circ}$ Si de clerico qui beneficio amovibili potitur, eum suspendat; et in decreto suspensiones expresse edicat, nisi clericus infra mensem ab eodem decreto computandum obedierit, beneficium ipso facto vacaturum. Mense inutiliter elapso, ordinarius beneficium vacans declaret".

100 Animadversiones [8]: "Can. 753 n 3 Ait: 'Si de clerico qui beneficio amovibili potitur' dicendum: 'qui beneficio inamovibili potitur" = "Can. $753 \mathrm{n}^{\circ} 3$ : Donde dice 'si el clérigo posee un beneficio amovible' debe decirse 'si posee un beneficio inamovible”".
} 
cumplía el precepto ni daba contestación, el ordinario, una vez que le constaba que el clérigo pudo hacerlo, "si pasados dos meses desde la suspensión no se enmienda, le privará de la mitad de los frutos del beneficio; después de otros tres meses, de todos los frutos beneficiales; y pasados otros tres más, del mismo beneficio" (can. 2177).

\section{CONCLUSIONES}

Llegados al final de estas páginas, en las que he revisado las observaciones que los obispos de la provincia eclesiástica chilena hicieron en marzo de 1914 al proyecto del libro IV, De delictis et poenis, y en junio de 1915 al proyecto de libro V, De iudiciis ecclesiasticis, del Código de Derecho Canónico que estaba preparándose en Roma, podemos sintetizarlas en las siguientes conclusiones:

1. El proyecto de ambos libros lo conocieron los obispos residenciales que había en esos momentos en Chile, en concreto, el arzobispo de Santiago, Juan Ignacio González Eyzaguirre, y los obispos de La Serena, Ramón Ángel Jara Ruz; de Concepción, Luis Enrique Izquierdo Vargas; y de Ancud, fray Pedro Armengol Valenzuela Poblete, O. de M., pues todas las diócesis estaban provistas de su propio obispo.

2. De los obispos que participaron en el informe, dos de ellos ya habían participado en el proceso de codificación que se llevaba adelante desde 1904. Uno de ellos era el obispo de Ancud, fray Pedro Armengol Valenzuela Poblete, O. de M., quien había sido incluido en la primera lista de consultores elaborada en dicho año al inicio mismo de la codificación canónica, mientras se desempeñaba en Roma como maestro general de la Orden de la Merced. El otro era el obispo de La Serena, Ramón Ángel Jara, quien había participado en 1904 en el primer informe enviado a Roma, cuando entonces era obispo de Ancud, no solo uniéndose al informe enviado por el arzobispo Mariano Casanova, sino agregando propuestas propias. Los otros dos prelados, el arzobispo de Santiago, Juan Ignacio González Eyzaguirre, y el obispo de Concepción, Luis Enrique Izquierdo Vargas se enfrentaron por primera vez al proceso codificador en 1914 cuando tuvieron que informar acerca del proyecto de libro IV.

3. Según las instrucciones que se dieron a los obispos, podían proceder al examen de los cánones contenidos en los proyectos valiéndose de uno o dos expertos en derecho canónico, clérigos regulares o seculares, quedando tanto los obispos como los consultores obligados al secreto pontificio. No hay antecedentes para afirmar que hubo algún o algunos consultores para elaborar el informe enviado a Roma, o, si es que lo(s) hubo(s), quiénes pudieron ser. En esto se distingue este informe del enviado a Roma con ocasión del informe acerca del proyecto de los libros I y II del Código Canónico en el que colaboró el presbítero Carlos Silva Cotapos, quien se desempeñaba como secretario de cámara del arzobispo. Al tiempo de enviarse el informe del libro IV, marzo de 1914, Carlos Silva todavía se desempeñaba como secretario de cámara; y al enviarse el informe del libro V, junio de 1915, ya era vicario general y provisor del arzobispado, por lo que es probable que el arzobispo lo haya consultado, pero no hay constancia alguna del hecho.

4. De los cuatro prelados consultados, solo formularon observaciones dos de ellos, el arzobispo de Santiago, Juan Ignacio González Eyzaguirre, y el obispo de Ancud, fray 
Pedro Armengol Valenzuela Poblete, O. de M.; de ambos, fue el primero el que más intervino, porque el obispo ancuditano tan solo hizo una observación al libro V. Los otros dos obispos, el de La Serena, Ramón Ángel Jara Ruz, y el de Concepción, Luis Enrique Izquierdo Vargas, no tuvieron observaciones que formular a ninguno de los dos proyectos.

5. Las observaciones al libro IV del proyecto, referido a los delitos y las penas fueron dos, ambas meramente formales. De ellas, una fue tomada en cuenta y la otra no. Es posible detectar si las observaciones episcopales fueron tomadas en cuenta por la tarjadura hecha sobre ellas en el original por el propio cardenal Gasparri al momento de revisarlas: aquellas que eran consideradas relevantes eran tarjadas con una línea de tinta; las demás quedaban igual como habían sido enviadas.

6. Las observaciones al libro $\mathrm{V}$ del proyecto, referido a los juicios eclesiásticos, fueron ocho, de las cuales cinco aparecen tarjadas y tres no, lo que significa que cinco de las ocho observaciones fueron consideradas interesantes por el cardenal Gasparri y conveniente tomarlas en cuenta.

7. Las cinco observaciones tarjadas, es decir, consideradas relevantes, fueron formuladas por el arzobispo González. La única observación formulada por un sufragáneo, en concreto el obispo de Ancud, no fue tomada en consideración, aun cuando apuntaba a un aspecto sustantivo.

8. De las cinco observaciones tomadas en consideración, tres eran simplemente formales: dos de ellas corregían remisiones erróneas hechas a otros cánones que no eran los correctos; la otra hacía presente que en opinión del arzobispo, el canon observado estaba trunco.

9. Las tres observaciones restantes que no fueron tomadas en consideración aportaban sugerencias más bien de contenido a los cánones de los proyectos. La observación del obispo de Ancud apuntaba a agregar un nuevo privilegio a los obispos, la que no fue tomada en consideración.

10. La segunda observación desechada era más bien una duda que le sugería al arzobispo la lectura de algunos cánones del proyecto, la que ilustraba planteando un caso. Fue la observación más extensa de todas las formuladas durante el proceso codificador y en ella proponía una interpretación que se alejaba de la solución planteada expresamente por el proyecto, primero, y por el mismo código, después, al entender que la segunda apelación podía verse por el mismo tribunal de apelación situado en Chile, en circunstancias que el proyecto entregaba el conocimiento de ella a la Rota Romana. La interpretación buscaba evitar tener que acudir a Roma por lo dispendioso en tiempo y recursos que significaba. Pero, como el mismo proyecto daba la solución, que no era precisamente la postulada por el arzobispo, la observación no fue tomada en cuenta.

11. La tercera observación desechada era también una simple aclaración a la comprensión de un canon. No fue tomada en cuenta, al parecer, porque se refería a una materia que, si bien estaba presente en el proyecto, fue finalmente dejada de lado en el código. 


\section{ANEXOS}

1

[Informe del arzobispo de Santiago con las observaciones al proyecto de libro IV, De delictis et poenis

Santiago, 12 de marzo de 1914

Archivio Segreto Vaticano, Commissione cod. Diritto Canonico, caja 84]

Sancti Jacobi, die 12 Martii 1914 / Eme Domne. / Honori sibi ducit infra scriptus archiepiscopus Sancti Jaco- / bi de Chile Emae Vestrae patefacere quae sequuntur Animadversiones in / IV Librum Schematis Codicis Juris Canonici ubi agitur de Delictis et / Poenis: /

I. Canon 76 non videtur recte digestus quum leges $\mathbb{S} 3$ et 4 et leges $\mathbb{} 1$ / et 2 . non satis arcto nexu teneantur. Lex enim $\$ 3$ forte canonem sepa- / ratum constituere poterir; et $\$ 4$ delendum erit quia idem statuit quod / canon $75 \mathrm{~S} 2 \%$

II. In canone 94 S 2 citatio can. 59 S 2 ita corrigenda: can. 59 \$3. [tarjado] /

Haec sunt quae in Libro prae memorato, post diligentem scru- / tationem, notanda duxi. Illmi. Antistites Suffraganei nihil censuerunt / animadvertendum. I

Emae Vestrae addictissimus in Christo frater / J. Ignatius Archiepiscopus Sancti Jacobi [firma] / Emo. Domno. Cardinali Pedro Gasparri. /

2

[Carta del arzobispo de Santiago al cardenal Pedro Gasparri enviando el informe con las observaciones al proyecto de libro V, De iudiciis ecclesiasticis

Santiago, 10 de junio de 1915

ARCHIVIO SEgRETO VATICANO,

Commissione cod. Diritto Canonico, caja 73]

Eme Dñe / Mihi vero gratum equidem / est, animadversiones quas opportunas / duxi in "Liber Quintus Codicis Juris / Canonici", addita ea quam Episcopus / S. Caroli Ancudiae fecit, Vestra Emi- I nentiae mittere. Ceteri Suffraganei, / Episcopi Smae. Conceptionis et Serenen- / sis nihil animadvertendi habuerunt. / Et Deus V. Eminentiae / J. Ignacio Arzobispo de Santiago [firma] / Sancti Jacobi de Chile, 10 junii 1915 / Emo Dno. Cardinali Petro Gasparri, / Commissionis Pontificiae legibus canonicis / in unum redigendis Praesidi. I

3

[Observaciones de los obispos de la provincia eclesiástica chilena al proyecto de libro V, De iudiciis ecclesiasticis

ARCHIVIO SEgReto VATICANO,

Commissione cod. Diritto Canonico, caja 73]

Animadversiones / Episcoporum Provinciae Ecclesiasticae / Chilensis in "Liber Quintus, de Judi- / ciis Ecclesiasticis”. I 
Can. 51. Hic canon est truncus. [tarjado] /

Can 258. "Eodem privilegio fruun- / tur Patres Cardinales", addatur: "atque / Episcopi" ut cohaereat cum canone / $266 n^{\circ} 1$ (Epus. Ancuditanus). I

Can. $390 n^{\circ}$ 3. Oportet ut rite expri- / matur hoc, nempe: utrum eae senten- / tiae sint validae necne, in quibus ea- / rumdem non exponantur rationes, seu / fundamenta. [tarjado]/

Can. 417. Juxta can. 67, ab Epi- / scopi sententia ad Metropolitanum ap-Ipellatur; a sententia autem Metropoli- Itani lata in prima instantia, ad alium / Ordinarium, sive Metropolitanum, aut / Episcopum appellatur, scilicet ad eum / qui ab ipso Metropolitano judex ap- I pellationum intra annum publicatio- I nis codicis cum S. Sedis appobatione / constitutus fuerit. Item, juxta can. 417, / duae sententiae conformes transeunt / in rem judicatam; ac tandem juxta / art. 72 num. 3, Sacra Rota, de senten- / tiis a quoqumque tribunali in secun- // da aut ulteriori instantia prolatis, a / quibus ad S. Sedem legitime appelle- / tur, definitive judicat. Quibus sup- / positis, sequens proponitur casus: I "Episcopus aut Archiepiscopus / sententiam profert in prima instan- / tia, quam judex appellationum revo- / cat. Litigantes appellare cupiunt, / sed minime ad S. Rotam, quia nimis / onerosae, cum procul absint ab Urbe, / farent expensae. Ad quemnam, igi- / tur, si vero juxta can. 67, neque ad / alium Metropolitanum, erunt appel- / laturi? Num ad S. Rotam appellare / tennentur, an fortasse in eo consentire, / quod sententia in secunda instantia / lata transeat in rem judicatam?" / Quod hoc in codice, solvi videtur, / modo can. 67 stabilitur quod in sen- / tentiis sive in prima aut secunda / instantia a quocumque Metropolitano / latis, sit appellationum judex Ordina- / rius a Metropolitano constitutus ad / hoc, salvo S. Rotae jure, quo ad ip- / sam de quacumque sententia in se- / cunda instantia lata appellari queat. I

Can. 517. Afferatur can. 516 pro / can. 518. [tarjado] /

Can. 682 S 1. Exprimi oportet quod // appellation eo inciso concesa, quod incipit: / "Sed si quis ex eodem decreto peculiare / jus suum violatum putet, etc.", vim ha- / beat tantum quoad effectum devoluti- / vum; secus ipsa appellatio nibil aliud / esset quam recursus dilatorius, ne quis / a beneficio suspenderetur. I

Can. 684. Afferatur can. 671 pro / can. 679. [tarjado] /

Can. $753 n^{\circ} 3$ [N.A.: debe decir can. $735 n^{\circ}$ 3]. Ait "Si de clerico / qui beneficio amovibili potitur": dicen- / dum: "qui beneficio inamovibili potitur". [tarjado] /

\section{BIBLIOGRAFÍA CITADA}

Alonso Morán, op., Sabino; Cabreros de AnTA, cmf., Marcelino (1964): Comentarios al Código de Derecho Canónico (Madrid, Biblioteca de Autores Cristianos), vol. III, $705 \mathrm{pp}$.

ARChivo Del ARZObispado De SANTIAGo (s.d.): Libro primero de actas de las sesiones celebradas por los Illmos. Señores arzobispo y obispos sufragáneos de Concepción, Serena y Ancud.

Archivio Segreto Vaticano. Commissione (Pontificia) per la codificazione del Diritto Canonico, Índice 1164. 
ArChivo SECREto VATICANO (2008-2009), Indice de los Fondos y relativos instrumentos de descripción de investigación (Ciudad del Vaticano).

Carta circular "Pergratum mihi, de 25 de marzo de 1904" (1903-1904), Acta Sancta Sedis, vol. 36, pp. 603-604.

Codex Iuris Canonici (1905): Postulata Episcoporum in ordinem digesta a Rmo. P. Bernardino Klumper, O. F. M. Consultore (Romae, Typis Vaticanis) 283 pp. ARCHIVIO Segreto Vaticano, Commissione cod. Diritto Canonico, caja 4.

CÓdigo DE DERECHO CANÓNICO (1983).

Diccionario de derecho canónico arreglado a la jurisprudencia eclesiástica española antigua y moderna (1859) (Paris) 1.124 pp.

Donoso, Justo (1849): Instituciones de derecho canónico americano (Valparaíso) vol. II, 480 pp.

DuCASSE Medina, Ignacio (2008): Servidores del Evangelio. Los obispos de Chile 15612007 (Conferencia Episcopal de Chile, Santiago) 342 pp.

FALCHI, Franceso (2006): "Interventi nella tavola rotonda", en: CATTANEO, Arturo (a cura di), L'eredità giuridica di san Pio X (Venezia, Marcianum Press) pp. 335-336.

FANTAPpIÈ, Carlo (2002): "Gl'inizi della codificazione pio-benedettina", Il diritto ecclesiastico vol. 113: pp. 16-83.

FANTAPPIÈ, Carlo (2008), Chiesa romana e modernità giuridica. L'edificazione del sistema canonistico (1563-1903) (Per la storia del pensiero giuridico moderno, vol. 76, Giuffrè, Milano) 2 vols.

GASPARRI, Pedro (1937): "Storia della codificazione del diritto canonico por la Chiesa latina”, en: PONTIFICIUM INSTITUTUM UTRIUSQUE IURIS, Acta congressus iuridici internationalis. VII saeculo a Decretalibus Gregorii IX et XIV a Codice Justiniano promulgatis. Romae 12-17 novembris 1934 (Romae) vol. IV, pp. 4-10.

GONZÁleZ ERrÁZURIZ, Juan Ignacio (2003): El arzobispo del centenario. Juan Ignacio González Errázuriz (Ediciones Centro de Estudios Bicentenario, Santiago) 400 pp.

Llobell, Joaquín; De LeÓn, Enrique; NAVARrete, Jesús (1999): Il libro "De processibus" nella codificazione del 1917. Studi e documenti (Milano, Giuffrè) 1.301 pp.

Oviedo Cavada, Carlos (1996); Los obispos de Chile (Santiago, Editorial Andrés Bello) $282 \mathrm{pp}$.

Retamal Fuentes, Fernando (2005): Chilensia Pontificia. Monumenta Ecclesiae Chilensia (Santiago, Ediciones Universidad Católica de Chile) vol. II, tomo III pp. 10041764.

RUfFINI, Francesco (1905): "La codificazione del diritto eclesiástico", en Studi di diritto in onore di Vittorio Scialoja (Milano) vol. II, pp. 353-391.

SAlinas ARAneda, Carlos (2008): "La codificación del derecho canónico de 1917", Revista de Derecho de la Pontificia Universidad Católica de Valparaíso, vol. 30, $1^{\mathrm{er}}$ semestre: pp. 311-356.

SALINAS ARANEDA, Carlos (2008): "El primer aporte de los obispos chilenos a la codificación del derecho canónico de 1917: los postulata episcoporum", Revista de estudios histórico-jurídicos, vol. 30: pp. 317-342. 
SAlinAS ARANEDA, Carlos (2008): "El primer aporte de los obispos chilenos a la codificación del derecho canónico de 1917: los 'postulata' del obispo de Ancud, Ramón Ángel Jara Ruz”, Boletín de la Academia Chilena de la Historia, vol. 117: pp. 161-189.

SAlinas ARANEDA, Carlos (2008): "El primer aporte de los obispos chilenos a la codificación del derecho canónico de 1917: los 'postulata episcoporum' acerca del matrimonio", Historia, vol. 41/2: pp. 413-446.

SAlinas ARANEDA, Carlos (2008): "El primer aporte de los obispos chilenos a la codificación del derecho canónico de 1917: los 'postulata' del obispo de Concepción, Plácido Labarca”, Revista de Derecho de la Universidad Católica de la Santísima Concepción, vol. 17/1: pp. 89-105.

SAlinas ARAneda, Carlos (2007): "Un manuscrito inédito del obispo chileno Rafael Fernández Concha: un proyecto parcial de Código de Derecho Canónico presentado con ocasión de la codificación canónica de 1917”, Revista de Estudios HistóricoJurídicos, vol. 29: pp. 481-514.

SAlinas Araneda, Carlos (2009): "Las observaciones de los obispos chilenos a los proyectos de libro I, Normae generales, y libro II, De personis, del Código de Derecho Canónico de 1917", Revista de Estudios Histórico-Jurídicos, vol. 31: en prensa

Schema Codicis Iuris Canonici (1912): Sub secreto pontificio. Sanctissimi Domini Nostri Pii PP. $X$ Codex Iuris Canonici cum notis Petri card. Gasparri (Typis polyglottis Vaticanis, Romae) 281 pp. Archivio Segreto Vaticano, Commissione cod. Diritto Canonico, caja 23.

Schema Codicis Iuris Canonici (1913). Sub secreto pontificio. Sanctissimi Domini Nostri Pii PP. X Codex Iuris Canonici cum notis Petri card. Gasparri (Typis polyglottis Vaticanis, Romae) 365 pp. ArChivio Segreto Vaticano, Commissione cod. Diritto Canonico, caja 51.

Schema Codicis Iuris Canonici (1913): Sub secreto pontificio. Sanctissimi Domini Nostri Pii PP. X Codex Iuris Canonici cum notis Petri card. Gasparri (Typis polyglottis Vaticanis, Romae) 106 pp. Archivio Segreto Vaticano, Commissione cod. Diritto Canonico, caja 79.

Schema Codicis Iuris Canonici (1914): Sub secreto pontificio. Codex Iuris Canonici cum notis Petri card. Gasparri (Typis polyglottis Vaticanis, Romae) 238 pp. ARCHIVIO Segreto Vaticano, Commissione cod. Diritto Canonico, caja 70.

Vetulani, Adam (1942), "Codex Juris Canonici”, Dictionnaire de Droit Canonique (Paris) vol. III, col. 930-933.

\section{NORMAS CITADAS}

Benedicto XIV, Constitución Dei miseratione, de 3 de noviembre de 1741. GASPARRI, Petri (1937), Codicis Iuris Canonici Fontes (Romae) vol. I, pp. 695-701.

Proyecto de Libro II, De personis, del Código de Derecho Canónico de 1917: cánones 168, 184. Archivio Segreto Vaticano, Commissione cod. Diritto Canonico, caja 23.

Proyecto de libro IV, De delictis et poenis, del Código de Derecho Canónico de 1917: cánones 59, 75, 76, 94. ArChivio Segreto Vaticano, Commissione cod. Diritto Canonico, caja 79 . 
Proyecto de libro V, De iudiciis ecclesiasticis, del Código de Derecho Canónico de 1917: cánones 8, 15, 51, 52, 67, $72 \mathrm{n}^{\circ}$ 3, 258, $266 \mathrm{n}^{\circ} 1,390 \mathrm{n}^{\circ}$ 3, 391, 392, 417, 516, 517, 518, 671, 679, 682 \$1, 684, 690, 708, $735 \$ 1 \mathrm{n}^{\circ} 3,753$ ”. ARCHIVIO Segreto Vaticano, Commissione cod. Diritto Canonico, caja 70.

Código de Derecho Canónico (1917): cánones $1579 \$ 3,1586,1594,1599$ n 2, 1605 , 1770, 1894, 1990, 1991, 2010, 2011, 2012, 2177, 2254\$3, 2271, 2272, $2290 \$ 2$. 
